$$
R F P-5267
$$

\title{
Reactions of Plutonium Dioxide with Water and Oxygen-Hydrogen Mixtures: Mechanisms for Corrosion of Uranium and Plutonium
}

\author{
by \\ John M. Haschke \\ 11003 Willow Bend Drive \\ Waco, TX 76712
}

\author{
Prepared for \\ Safe Sites of Colorado, LLC \\ Rocky Flats Environmental Technology Site \\ Golden, $\mathrm{CO}$
}

June18, 1999 


\title{
Reactions of Plutonium Dioxide with Water and Oxygen-Hydrogen Mixtures: Mechanisms for Corrosion of Uranium and Plutonium
}

\author{
John M. Haschke \\ 11003 Willow Bend Drive \\ Waco, TX, 76712, USA \\ Thomas H. Allen and Luis A. Morales \\ Los Alamos National Laboratory \\ PO Box 1663, Los Alamos NM, 87545, USA
}

\begin{abstract}
Investigation of the interactions of plutonium dioxide with water vapor and with an oxygen-hydrogen mixture show that the oxide is both chemically reactive and catalytically active. Water dissociatively adsorbs on the oxide below $100^{\circ} \mathrm{C}$ and desorbs at higher temperatures, while reacting at a relatively slow rate to form a higher oxide, $\mathrm{PuO}_{2+\times}$, and $\mathrm{H}_{2}$. Exposure of a 2:1 mixture of $\mathrm{H}_{2}+\mathrm{O}_{2}$ to the dioxide at $25^{\circ} \mathrm{C}$ results in surface-catalyzed formation of water, a product that subsequently reacts via a catalytic cycle that consumes $\mathrm{O}_{2}$ and forms $\mathrm{PuO}_{2+x}$ at the relatively rapid rate of the $\mathrm{PuO}_{2}+\mathrm{H}_{2} \mathrm{O}$ reaction, maintains a constant $\mathrm{H}_{2} \mathrm{O}$ concentration in the system, but does not generate $\mathrm{H}_{2}$. Correspondence of this chemical behavior with that for oxidation of uranium in moist air suggests that similar catalytic processes participate in the mechanism of moisture-enhanced corrosion of uranium and plutonium. Evaluation of chemical and kinetic data for corrosion of the metals leads to a comprehensive mechanism for corrosion in dry air, water vapor, and moist air. In all cases, the corrosion rate is controlled by the same process of oxygen diffusion through the layer of oxide product on the metal surface. The corrosion rate is altered as adsorption and desorption of water changes the gradient in oxygen concentration across the oxide layer. The proposed mechanism is described in detail and a possible explanation for throttled enhancement of the uranium corrosion rate in moist air is suggested. Results are applied in confirming that the corrosion rate of $\mathrm{Pu}$ in water vapor decreases sharply between 100 and $200^{\circ} \mathrm{C}$.
\end{abstract}

\section{Introduction}

Oxidation and other corrosion reactions of uranium and plutonium are of special concern because these actinides are used extensively in commercial and military applications. In addition to transforming massive metal into a dispersible material form, corrosion may cause failure of containment vessels by expanding the solid phase or forming noncondensable gases [1]. Although uranium and plutonium oxidize slowly in dry air or oxygen, their corrosion rates are marked enhanced by the presence of moisture. As shown in recent reports describing the oxidation kinetics of the metals over broad ranges of temperature and humidity, the corrosion rates of $U$ and $\mathrm{Pu}$ in water vapor are 


\section{DISCLAIMER}

This report was prepared as an account of work sponsored by an agency of the United States Government. Neither the United States Government nor any agency thereof, nor any of their employees, make any warranty, express or implied, or assumes any legal liability or responsibility for the accuracy, completeness, or usefulness of any information, apparatus, product, or process disclosed, or represents that its use would not infringe privately owned rights. Reference herein to any specific commercial product, process, or service by trade name, trademark, manufacturer, or otherwise does not necessarily constitute or imply its endorsement, recommendation, or favoring by the United States Government or any agency thereof. The views and opinions of authors expressed herein do not necessarily state or reflect those of the United States Government or any agency thereof. 


\section{DISCLAIMER}

Portions of this document may be illegible in electronic image products. Images are produced from the best available original document. 
more than $10^{2}$ and $10^{5}$ faster than in dry air, respectively $[2,3]$. Effects of water concentrations as low as 1 ppm are evident during corrosion of unalloyed Pu in air [4]. Such behavior necessitates the use of strict moisture-control methods during storage and use of uranium and plutonium, but the nature of the enhancement process has remained speculative.

A kinetic feature of comparable importance to the enhancement process is the disappearance of such effects and entry into moisture-independent kinetic regimes at elevated temperatures. At high temperatures, both metals oxidize at the same isobaric rates in water vapor as they do in dry air or dry oxygen. For uranium, the transition to moistureindependent behavior occurs gradually over the $250-500^{\circ} \mathrm{C}$ range [2]. For plutonium, the change appears rather abruptly between 110 and $200^{\circ} \mathrm{C}[3,4]$, a temperature consistent with an early report that moisture has no kinetic effect above $215^{\circ} \mathrm{C}$ [5]. This change causes the rate to decrease by as much as $10^{4}$ as the temperature increases and significantly improves the margin of safety for potentially pyrophoric waste forms containing plutonium metal by preventing runaway reaction of $\mathrm{Pu}$ with $\mathrm{H}_{2} \mathrm{O}$ at temperatures below $200^{\circ} \mathrm{C}[6]$. Confidence in the ability to manage phenomena such as corrosion and autothermic reaction depends on understanding both the chemistry and mechanism of the moisture-enhanced oxidation.

Surprisingly similar kinetic behavior is observed for uranium and plutonium in dry air and water vapor [2,3]. At room temperature, the oxidation rates of $U$ and $P u$ in dry air are essentially identical at 0.8 and $0.5 \mathrm{ng}$ metal $\mathrm{cm}^{-2} \mathrm{~min}^{-1}$, respectively. The activation energy of $67 \mathrm{~kJ} \mathrm{~mol}^{-1}$ (16 kcal mol$^{-1}$ ) for dry oxidation of uranium corresponds closely with the $79 \mathrm{~kJ} \mathrm{~mol}^{-1}$ (19 $\left.\mathrm{kcal} \mathrm{mol}^{-1}\right)$ value for plutonium. Whereas exposure of $U$ to saturated water vapor at $25^{\circ} \mathrm{C}$ increases the corrosion rate by a factor of 400 , exposure to that condition causes a 250 -fold increase in the rate for $\mathrm{Pu}$. At temperatures below the transition points to moisture-independent oxidation, the corrosion rate of each metal is bounded by the slow rate in dry air or oxygen and the rapid rate in water vapor. Convergence of these Arrhenius curves at the transition point closes a temperature-humidity envelope that confines the corrosion kinetics of each metal in humid air at low temperatures. Although differences are observed in the shapes of the envelopes and in kinetic behavior of $U$ and Pu within the envelopes, the corrosion reactions of the two metals in air are remarkably similar and apparently proceed by the same kinetic process. Therefore, combination of result for uranium and plutonium provides a significantly expanded set of chemical and kinetic observations for interpreting moisture-enhanced corrosion of these actinides. 
We employ data from experimental and literature sources in describing the reactions of uranium and plutonium with dry air (equivalent to dry oxygen), with water vapor, and with moist air (equivalent to moist oxygen). Observations are applied in deriving a comprehensive mechanism that accounts for corrosion in dry and moist conditions, as well as for the absence of enhancement at elevated temperatures. Consideration of surface and bulk properties of the oxide layer formed on the metal during corrosion suggests that corrosion rates in these atmospheres differ because of chemical process occurring at the gas-oxide interface. Our development of the mechanism is greatly facilitated by results of experiments that examine interactions of plutonium dioxide with water vapor and with a mixture of hydrogen and oxygen.

\section{Experimental methods}

Chemical and kinetic behavior of the gas-oxide systems were investigated over the 25$250^{\circ} \mathrm{C}$ range using microbalance $(\mathrm{MB})$ and pressure-volume-temperature (PVT) methods $[7,8]$. During these tests, $\mathrm{PuO}_{2}$ was exposed to water vapor or to a mixture of hydrogen and oxygen. Kinetic data were obtained by measuring mass or pressure changes as a function of time $(t)$.

Dioxide specimens were prepared by oxidation of the metal. The plutonium oxide specimens used in MB measurements were from the dioxide used in an earlier investigation [9]. The oxide ( $4.8 \mathrm{~m}^{2} \mathrm{~g}^{-1}$ specific surface area) was formed by atmospheric oxidation of electrorefined alpha-phase metal containing approximately $100 \mathrm{ppm}$ Am as the major metallic impurity. The oxide stoichiometry was obtained using the measured lattice parameter $\left(a_{0}=5.4037 \AA\right)$ of the cubic oxide and a correlation of $a_{0}$ with O:Pu ratio [7] based on data reported by Gardner et al. [10]. The $\mathrm{PuO}_{2}$ used in PVT studies was prepared by oxidizing weapons-grade gallium alloy in a volume-calibrated stainless steel system. An accurately weighed metal specimen $(10.2 \mathrm{~g})$ was placed in a oxide-coated stainless steel crucible and transformed into powder by repeated cycles of hydriding at room temperature and dehydriding at $450-500^{\circ} \mathrm{C}$ in dynamic vacuum and then oxidized at $500^{\circ} \mathrm{C}$ in highpurity $\mathrm{O}_{2}$. The product was ground in an inert atmosphere glovebox and reheated in excess oxygen until the total uptake of oxygen corresponded to the $\mathrm{PuO}_{2.00}$ composition, before being vacuum outgassed at $700^{\circ} \mathrm{C}$ and cooled to room temperature in 1.0 bar $\mathrm{O}_{2}$. A specific surface area of $4 \pm 3 \mathrm{~m}^{2} \mathrm{~g}^{-1}$ was estimated using a correlation of the specific area with firing temperature [9].

Microbalance measurements of the interaction between $\mathrm{PuO}_{2}$ and $\mathrm{H}_{2} \mathrm{O}$ were made with a Cahn RH microbalance located in an inert-atmosphere glovebox [7]. Oxide specimens 
(approximately $0.1 \mathrm{~g}$ ) were accurately weighed prior to placement in the $\mathrm{Pt}$ sample container. The oxide was outgassed to constant mass in vacuum at $400^{\circ} \mathrm{C}$ and was then exposed to water pressure at 15 torr as the temperature was increased stepwise from $25^{\circ} \mathrm{C}$ to $50,100,150$, and $250^{\circ} \mathrm{C}$ over a period in excess of 110 hours. Water vapor was introduced into the evacuated balance chamber via a gas manifold system and was maintained at a constant pressure with a water reservoir held at a fixed temperature. A constant sample temperature was maintained with a programmable controller and was measured by a thermocouple placed near the specimen. The mass of the specimen was measured as a function of time. XRD data for sample of the final product were obtained using a 114.56-mm-diameter Debye-Scherrer camera with CuK-alpha radiation.

Interaction of plutonium oxide with hydrogen and oxygen at $24.5 \pm 0.8^{\circ} \mathrm{C}$ was investigated by exposing $\mathrm{PuO}_{2}$ to a 2:1 molar mixture of $\mathrm{D}_{2}$ and $\mathrm{O}_{2}$. The crucible and prepared oxide were placed in a stainless steel PVT reactor $\left(40.0 \pm 0.1 \mathrm{~cm}^{3}\right.$ free volume) fitted with metallic seals, pressure transducers, and internal thermocouples. The evacuated reactor was charged with a low pressure ( 126.7 torr) of a gas mixture prepared by two-step pressurization of a small stainless steel reservoir with $\mathrm{D}_{2}(99.9 \%)$ and $\mathrm{O}_{2}(99.99 \%)$ at a $2: 1$ ratio. The atmosphere in this test reactor was monitored by continuous measurement of pressure and temperature and by periodic sampling for mass spectrometric (MS) analysis with a quadrapole instrument. Spectra were corrected for fragmentation and ionization cross section. Sample volumes $\left(0.37 \mathrm{~cm}^{3}\right)$ were sufficiently small that the chemical process was not disrupted by sampling. Deuterium was used in gas-mixture experiments to investigate hydrogen exchange between gaseous and condensed phases, but that concern is not pertinent to this study and a distinction between the $\mathrm{D}$ and $\mathrm{H}$ isotopes is not maintained.

Kinetic results were derived from mass-t and P-t data and from results of periodic MS analyses. Reaction rates $(R)$ are based on measured changes in pressure over time. Pressures were corrected for temperature variation and sampling and were assumed to behave ideally. Rates are reported in units of moles of gas reacted or formed per gram of oxide or square meter of oxide surface per unit time.

\section{Results and discussion}

\subsection{Interaction of $\mathrm{PuO}_{2}$ with $\mathrm{H}_{2} \mathrm{O}$}

Mass-time data obtained during exposure of the oxide to water vapor at 15 torr pressure show complex behavior as the temperature was incremental increased from 25 to $250^{\circ} \mathrm{C}$. A mass increase of about $0.40 \mathrm{mg} \mathrm{m}^{-2}$ was observed during a two-hour period following exposure of the oxide to water vapor at $25^{\circ} \mathrm{C}$. The oxide mass remained stable for 5 hours 
at $25^{\circ} \mathrm{C}$ and did not change when the temperature was held at $50^{\circ} \mathrm{C}$ for 7 hours. An additional weight gain of approximately $0.45 \mathrm{mg} \mathrm{m}^{-2}$ was observed over a period of 15 hours after the specimen temperature was raised to $100^{\circ} \mathrm{C}$. A mass loss of $0.83 \mathrm{mg} \mathrm{m}^{-1}$ occurred at a progressively decreasing rate over a period of 20 hours after the oxide was heated to $150^{\circ} \mathrm{C}$. The mass remained constant for approximately 1 hour after the temperature was raised to $250^{\circ} \mathrm{C}$ and then increased at a constant rate of $200 \pm 50 \mathrm{nmol}$ $\mathrm{H}_{2} \mathrm{O} \mathrm{m}^{-2} \mathrm{~h}^{-1}$ until that measurement was terminated after 65 hours. A mass gain of approximately $0.6 \mathrm{mg} \mathrm{m}^{-2}$ was observed after the sample was cooled to $25^{\circ} \mathrm{C}$.

$\mathrm{XRD}$ analysis of the product formed during incremental heating to $250^{\circ} \mathrm{C}$ showed a fluorite lattice like that for $\mathrm{PuO}_{2}$. The value of $\mathrm{a}_{\mathrm{o}}$ derived from the data was $5.3998 \AA$, a parameter that is $0.004 \AA$ smaller than that of the starting oxide.

Interpretation of the mass-time data draws on the results of recent studies describing adsorption of water on the dioxide at low temperatures [11] and chemical reaction of water with the dioxide at elevated temperatures [8]. Exposure of fired $\mathrm{PuO}_{2}$ to moist air at $25^{\circ} \mathrm{C}$ results in adsorption of water in a sequence of steps that vary in nature from strong chemisorption on clean oxide surfaces to weak physisorption of molecular water near saturation. Experimental and theoretical results show that adsorption of each molecular layer of $\mathrm{H}_{2} \mathrm{O}$ is accompanied by a mass gain of $0.2 \mathrm{mg} \mathrm{m}^{-2}$ of oxide surface. Mass-time data show that the first and second adsorption steps are complete in 1-2 hours at relative humidities less than $1 \%\left(0.24\right.$ torr $\mathrm{H}_{2} \mathrm{O}$ pressure) and that each step involves a mass gain of $0.1 \mathrm{mg} \mathrm{m}^{-2}$. These steps are attributed to dissociative chemisorption of water in processes involving adsorption of $\mathrm{H}_{2} \mathrm{O}$, reaction with lattice oxide ions at the gas-oxide interface, and formation of hydroxide ions plus an anion vacancy $(V)$ in the lattice.

$$
\begin{gathered}
\mathrm{H}_{2} \mathrm{O}(\mathrm{g}) \leftrightarrow \mathrm{H}_{2} \mathrm{O} \text { (ads) } \\
\mathrm{H}_{2} \mathrm{O} \text { (ads) }+\mathrm{O}^{2} \text { (lat) } \rightarrow 2 \mathrm{OH}^{-} \text {(ads) }+\mathrm{V} \text { (lat) } .
\end{gathered}
$$

Each $0.1 \mathrm{mg} \mathrm{m}^{-2}$ of adsorbed water forms a monolayer of hydroxide. If the relative humidity at $25^{\circ} \mathrm{C}$ is in the $5-60 \%$ (1-14 tor $\mathrm{H}_{2} \mathrm{O}$ pressure) range, a monolayer of $\mathrm{H}_{2} \mathrm{O}$ $\left(0.2 \mathrm{mg} \mathrm{m}^{-2}\right)$ adsorbs on the $\mathrm{PuO}(\mathrm{OH})_{2}$ surface formed by the dissociative reactions. Further increases in humidity at $25^{\circ} \mathrm{C}$ result in step-wise adsorption of additional molecular water and accommodation of approximately 10 layers of $\mathrm{H}_{2} \mathrm{O}$ on the oxide surface at saturation.

MB and PVT measurements show that the dominant interaction of plutonium dioxide with water at elevated temperatures is chemical reaction to form a higher oxide $\left(\mathrm{PuO}_{2+\mathrm{x}}\right)$ and hydrogen $[4,8]$. 


$$
\mathrm{PuO}_{2}(\mathrm{~s})+\mathrm{x} \mathrm{H}_{2} \mathrm{O}(\mathrm{ads}) \rightarrow \mathrm{PuO}_{2+x}(\mathrm{~s})+\mathrm{xH}_{2} \text {. }
$$

The activation energy of $39 \pm 3 \mathrm{~kJ} \mathrm{~mol}^{-1}\left(9.4 \pm 0.6 \mathrm{kcal} \mathrm{mol}^{-1}\right)$ is reflected in rates measured at $25^{\circ} \mathrm{C}\left(0.2 \mathrm{nmol} \mathrm{H}_{2} \mathrm{O} \mathrm{m}^{-2} \mathrm{~h}^{-1}\right)$ and $250^{\circ} \mathrm{C}\left(200 \mathrm{nmol} \mathrm{H}_{2} \mathrm{Om}^{-2} \mathrm{~h}^{-1}\right)$. Detailed descriptions of reaction kinetics and product properties are being published separately, but the results presented here provide essential information for evaluating the interaction of $\mathrm{PuO}_{2}$ with $\mathrm{H}_{2} \mathrm{O}$.

Gravimetric results obtained during incremental heating of the dioxide in water vapor are consistent with earlier observations. As determined in the previous study [11], the gain of $0.4 \mathrm{mg} \mathrm{m}^{-2}$ at $25^{\circ} \mathrm{C}$ is attributed to dissociative chemisorption of $0.2 \mathrm{mg} \mathrm{m}^{-2} \mathrm{H}_{2} \mathrm{O}$ as two layers of hydroxide and physisorption of a layer of molecular water on the resulting $\mathrm{PuO}(\mathrm{OH})_{2}$ surface. Likewise, the rate of mass increase observed at $250^{\circ} \mathrm{C}$ is in precise agreement with that for formation of $\mathrm{PuO}_{2+x}$ according to Equation 2. Formation of $\mathrm{PuO}_{2+x}$ is verified by $\mathrm{XRD}$ results showing that the lattice parameter of the product oxide corresponds to that for $\mathrm{PuO}_{2.013}$ [8]. Although further interaction of water is not seen at $50^{\circ} \mathrm{C}$, the additional increase of $0.4 \mathrm{mg} \mathrm{m}^{-2}$ observed at $100^{\circ} \mathrm{C}$ suggests that the equilibrium state for adsorption of water was not attained at lower temperatures or that the surface area of the oxide increased during heating. Formation of $\mathrm{Pu}(\mathrm{OH})_{4}$ by further hydration of the surface oxide accounts for half of the observed increase. Adsorption of an additional water layer or formation of a $\mathrm{Pu}(\mathrm{OH})_{6}$ surface layer is necessary to account for the entire mass increase. The later process seems very unlikely because the rate of Equation 2 at $100^{\circ} \mathrm{C}$ is too slow to form sufficient Pu(VI). A increase of $50 \%$ in the surface area of the oxide is suggested by the mass gain observed upon cooling to $25^{\circ} \mathrm{C}$. The additional adsorption at $100^{\circ} \mathrm{C}$ is consistent with formation of a Pu(OH $)_{4}$ surface and an increase of $40 \%$ in the specific surface area.

Experimental results verify that the adsorption is the predominant interaction of the dioxide with water at temperatures up to $100^{\circ} \mathrm{C}$. Kinetics are extremely important. Adsorption of additional water upon heating to $100^{\circ} \mathrm{C}$ suggests that equilibrium is not attained at 25 and $50^{\circ} \mathrm{C}$ because of slow kinetics. The surface configuration reached at lower temperatures is viewed as a metastable state formed by rapid adsorption processes. A more stable adsorbate configuration is apparently attained slowly at $100^{\circ} \mathrm{C}$, but that state is also metastable because adsorbed water reacts at an even slower rate to form $\mathrm{PuO}_{2+\mathrm{x}}$ and $\mathrm{H}_{2}$ according to Equation 2. Observations are consistent with prior kinetic results showing that the metastable states involve dissociative chemisorption of water as hydroxide and by physisorption of molecular water [11]. Reversibility of the adsorption processes is demonstrated by complete thermal desorption at $150^{\circ} \mathrm{C}$. 


\subsection{Interaction of $\mathrm{PuO}_{2}$ with an $\mathrm{H}_{2}+\mathrm{O}_{2}$ mixture}

Mixtures of hydrogen and oxygen are not thermodynamically stable and react to form water at a measurable rate in the presence of plutonium dioxide at room temperature. As shown by the P-t data in Figure 1, the pressure of the mixture dropped initially at a comparatively rapid rate, decreased at a progressively slower rate over time, and ultimately approached a constant rate of decrease. Data presented in Table 1 show that the rate of pressure decrease slowed by a factor of fifty during the first 70 days and was constant at longer times. Gas-phase compositions listed in Table 2 show the presence of $\mathrm{H}_{2}, \mathrm{O}_{2}$, and trace amounts of $\mathrm{CO}$ and $\mathrm{CO}_{2}$, but $\mathrm{H}_{2} \mathrm{O}$ is not observed. These data show that the $\mathrm{H}_{2}: \mathrm{O}_{2}$ ratio was 2.27 (not 2.00) in the initial mixture and increased progressively to 2.75 after 72 days. Increases are also observed in the fractions of $\mathrm{H}_{2}, \mathrm{CO}$, and $\mathrm{CO}_{2}$ over time. Observed and calculated quantities of reactants and products in the PVT reactor at zero time and after 72 days are presented in Table 3.

Our interpretation of these results is based on the assumption that the pressure decrease in Figure 1 results from reaction of -oxygen and hydrogen to form water. .

$$
\mathrm{H}_{2}(\mathrm{~g})+1 / 2 \mathrm{O}_{2}(\mathrm{~g})->\mathrm{H}_{2} \mathrm{O}(\mathrm{g}) \text {. }
$$

We also conclude that like $\mathrm{ThO}_{2}$ and $\mathrm{UO}_{2}[12], \mathrm{PuO}_{2}$ is a heterogeneous catalyst with capability for promoting combination of gaseous reactants.

The parametric dependencies of the $\mathrm{H}_{2}+\mathrm{O}_{2}$ reaction rate are defined by a general expression that includes temperature and the pressures of the gaseous reactants.

$$
\mathrm{R}=\operatorname{kexp}\left(-\mathrm{E}_{2} / \mathrm{R}^{*} \mathrm{~T}\right)\left(\mathrm{PO}_{2}\right)^{u}\left(\mathrm{PH}_{2}\right)^{\mathrm{r}}
$$

$\mathrm{R}$ is a function of a proportionality constant $(\mathrm{k})$, temperature, oxygen pressure $\left(\mathrm{PO}_{2}\right)$, and hydrogen pressure $\left(\mathrm{PH}_{2}\right)$. The temperature dependence is described by the exponential Arrhenius term, which includes the activation energy $\left(E_{2}\right)$ and gas constant $\left(R^{*}\right)$. The exponents $u$ and $v$ define the dependencies of $\mathrm{R}$ on the pressures of oxygen and hydrogen, respectively. Values of $u$ and $v$ cannot be determined from available data, but advantage is gained by fixing the gas-phase composition near the $2: 1 \mathrm{H}_{2}: \mathrm{O}_{2}$ ratio of the elements in water. Formation of water by mixtures with compositions far from the $2: 1$ ratio results in preferential depletion of one reactant and enrichment of the other as reaction proceeds, a condition that progressively changes gas-phase stoichiometry and may alter kinetic behavior. As discussed later, the absence of a precise $2: 1 \mathrm{H}_{2}: \mathrm{O}_{2}$ mixture at the start of the measurements is immaterial because the ratio inherently increases over time.

Reaction of an ideal 2:1 mixture of $\mathrm{H}_{2}$ and $\mathrm{O}_{2}$ confines the system to a constantcomposition section of P-t space defined by the total pressure of the gas mixture. At 
constant temperature and stoichiometric ratio, the rate expression reduces to a function of the total pressure of the gas mixture.

$$
\mathrm{R}=\mathrm{k}^{\prime}(\mathrm{P})^{\mathrm{n}} \text {. }
$$

The value of $\boldsymbol{n}$ is readily derived from experimental data by determining the slope of the InR-InP curve.

The observed increase in hydrogen to oxygen ratio of the experimental gas mixture results from the combined effects of stoichiometry-driven enrichment and chemical reaction. All reaction causes enrichment in components initially present in excess of the stoichiometric ratio. In this case, the $\mathrm{H}_{2}: \mathrm{O}_{2}$ ratio of the initial mixture exceeded the theoretical ratio by about $13 \%$. Although an error in preparation of the mixture cannot be excluded, the ratio may have been increased by stripping of higher-molecular-weight $\mathrm{O}_{2}$ as the PVT reactor was slowly filled with the gas mixture through a precision valve. Regardless of its origin, the high initial ratio results in hydrogen enrichment as reaction proceeds. However, as shown by data in Table 3, the theoretical 2.41:1 ratio defined by the calculated amount $(133.6 \mu \mathrm{mol})$ of $\mathrm{H}_{2}$ present after 72 days and the measured amount (55.4 $\mu \mathrm{mol}$ ) of $\mathrm{O}_{2}$ present at that point does not account for the observed ratio of 2.75:1. The measured quantity of hydrogen present at that point exceeds the anticipated amount by $19.0 \mu \mathrm{mol}$ and implies that water formed via Equation 4 is simultaneously reacting with the oxide to form hydrogen according to Equation 3.

Our conclusion that the $\mathrm{PuO}_{2}+\mathrm{H}_{2} \mathrm{O}$ reaction contributes to the increase in the $\mathrm{H}_{2}: \mathrm{O}_{2}$ ratio of the gas mixture is supported by kinetic results. The average formation rate of hydrogen during the initial 72 days is defined by the oxide mass and the amount of excess $\mathrm{H}_{2}$ formed during that period. The rate of $23 \mathrm{nmol} \mathrm{H}_{2} \mathrm{~g}^{-1} \mathrm{~d}^{-1}\left(6 \mathrm{nmol} \mathrm{H}_{2} \mathrm{~m}^{-2} \mathrm{~d}^{-1}\right)$ derived from these data is in excellent agreement with the value of $12 \mathrm{nmol} \mathrm{H}_{2} \mathrm{~g}^{-1} \mathrm{~d}^{-1}$ measured during exposure of oxide to water at $25^{\circ} \mathrm{C}$ [7]. The true rates of water formation by the hydrogenoxygen mixture are faster than indicated by the experimental values and are corrected for hydrogen generation in Table 1 . Beyond 70 days, the corrected rate of $\mathrm{H}_{2} \mathrm{O}$ formation equals the rate at which $\mathrm{H}_{2}$ is formed by the $\mathrm{PuO}_{2}+\mathrm{H}_{2} \mathrm{O}$ reaction. In this region, water and hydrogen are present in steady-state concentrations and the observed pressure decrease results solely from disappearance of $\mathrm{O}_{2}$.

Dependence of the $\mathrm{H}_{2}+\mathrm{O}_{2}$ reaction rate on pressure in the presence of $\mathrm{PuO}_{2}$ is shown by the InR-InP curve in Figure 2. Appearance of two well-defined linear regions suggests that a change in reaction mechanism occurs at $\ln P=4.79$, a point reached after 4.0 days and a decrease of about $5 \%$ (6.5 torr) in pressure. As defined by slopes of the linear segments, values of $n$ in the high-pressure and low-pressure regimes are 46.7 and 5.9 , 
respectively. In the linear $\mathrm{P}-\mathrm{t}$ region beyond 70 days, $\mathrm{R}$ is constant, and $\boldsymbol{n}$ is zero. A fortyseventh-order pressure dependence has no rational interpretation, and the $\ln R-\ln P$ relationship predicts that extremely large rate changes are caused by modest pressure changes. For example, the predicted reaction rate at a mixture pressure of 760 torr exceeds $10^{26} \mathrm{~mol} \mathrm{H}_{2} \mathrm{Oliter}^{-1} \mathrm{~s}^{-1}$. This result is totally unreasonable, and even a sixth-order dependence cannot be explained. Although the measured pressure exponents accurately describe kinetic behavior of the experimental systems during our test, they are not general applicable for defining rates of $\mathrm{H}_{2}+\mathrm{O}_{2}$ mixtures exposed to $\mathrm{PuO}_{2}$. However, the values of $n$ are instructive in defining the fundamental nature of the $\mathrm{H}_{2}+\mathrm{O}_{2}$ reaction.

The pressure dependence is applicable in determining if hydrogen and oxygen react in the gas phase or on a surface and if the reaction is radiolytic or chemical. Both issues are addressed by considering the magnitude of $n$. Neither the extremely large pressure dependence observed initially nor the sharp change in the exponent is consistent with a gasphase reaction. The behavior is best explained as an apparent pressure dependence that occurs as water produced by the $\mathrm{H}_{2}+\mathrm{O}_{2}$ reaction adsorbs at catalytic sites on the $\mathrm{PuO}_{2}$ surface. The rate of combination slows with decreasing pressure as product water chemisorbs at the most active sites first and then progressively blocks the most active available sites. The abrupt change in rate after 4 days is attributed to blockage of all sites in a distribution of highly active sites. A sixth-order pressure dependence is observed as subsequent reaction occurs at locations in a distribution of sites with relatively low catalytic activity. Reaction continues at these lower-activity sites during the steady-state process characterized by $n=0$.

Radiolytic promotion of gas-phase combination of $\mathrm{H}_{2}$ and $\mathrm{O}_{2}$ is inconsistent with the observed pressure dependence. Consideration of that possibility is merited because water forms in $2: 1 \mathrm{H}_{2}: \mathrm{O}_{2}$ mixtures at pressures in the 2 to 1000 torr range by gas-phase thermal reaction near $400^{\circ} \mathrm{C}$ and by explosive reaction at temperatures above $580^{\circ} \mathrm{C}$ [13]. Radiolytic reaction of a material depends on the alpha flux and the rate of energy loss in the material. The primary mechanism for loss of energy by $\mathrm{He}^{2+}$ in matter is coulombic interaction with electrons and formation of ion pairs [14]. Therefore, the rates of energy loss and radiolysis depend on material density, a property determined by the pressure of an ideal gas. A change in pressure is expected to introduce a proportionate change in the radiolytic rate. However, in the present experiment, a $23 \%$ decrease in the pressure of the $\mathrm{H}_{2}+\mathrm{O}_{2}$ mixture during the initial 70 days was accompanied by a 50 -fold rate decrease. This behavior is not consistent with that anticipated for a gas-phase radiolysis process. 
Formation of water by dissociation and chemical reaction of hydrogen and oxygen on the oxide surface is the only consistent explanation for the observed behavior.

Occurrence of the surface-catalyzed combination reaction at $25^{\circ} \mathrm{C}$ is demonstrated by appearance of water in the $\mathrm{H}_{2}: \mathrm{O}_{2}$ mixture retained for use as an analytical reference. The presence of $\mathrm{H}_{2} \mathrm{O}$ was shown by MS analysis of a sample from the stainless steel reservoir after 24 days. Formation of water on oxide-coated stainless steel by hydrogen is a wellknown non-radiolytic process that is responsible for significant background pressures of water in stainless systems during studies with $\mathrm{H}_{2}[15]$. Application of a potassium chloride coating to reactor walls is apparently necessary to provide a surface with a sufficiently low catalytic activity for studying gas-phase kinetics of $\mathrm{H}_{2}+\mathrm{O}_{2}$ mixtures [13].

The absence of water in the mass spectra of gas samples taken during exposure to plutonium dioxide is consistent with strong chemisorption of water by the oxide. Formation of $\mathrm{H}_{2} \mathrm{O}$ is demonstrated by the disappearance of $\mathrm{H}_{2}$ and $\mathrm{O}_{2}$ and by its reaction with $\mathrm{PuO}_{2}$ to form $\mathrm{H}_{2}$. The total amount of water $(69 \mu \mathrm{mol})$ produced during the initial 150 days of the test is insufficient to complete the first chemisorbed layer of hydroxide. The water pressure in equilibrium with the $\mathrm{PuO}(\mathrm{OH})_{2}$ product at $25^{\circ} \mathrm{C}$ is undoubtedly below the mass spectrometric detection limit. Consequently, the net reaction for combination of $\mathrm{H}_{2}$ and $\mathrm{O}_{2}$ on the $\mathrm{PuO}_{2}$ surface at room temperature is more accurately described by Equation 7 than by Equation 4 .

$$
\mathrm{H}_{2}(\mathrm{~g})+1 / 2 \mathrm{O}_{2}(\mathrm{~g})-->\mathrm{H}_{2} \mathrm{O} \text { (ads) . }
$$

This reaction implies that $\mathrm{H}_{2}$ and $\mathrm{O}_{2}$ adsorb and dissociate on the oxide surface prior to reaction and that $\mathrm{H}_{2} \mathrm{O}$ formed by their combination remains adsorbed on the oxide surface.

The fractional coverage $(\theta)$ of the oxide surface by hydroxide is readily derived as a function of time from the kinetic results. The coverages listed in Table 4 are based on the estimated surface area of the oxide and the quantity of water remaining in the reactor at each point in time. The amounts of water lost and formed are defined by P-t data in Table 1 and MS data in Table 2. Coverage of the surface by hydroxide is about $3 \%$ after 4 days, suggesting that this fraction of the oxide surface has high catalytic activity and is responsible for the rapid initial formation of water. The percent of surface coverage increases progressively until a steady-state concentration near $16 \%$ is established after 70 days. Beyond this point, the coverage and catalytic activity of the oxide surface are constant, the rates of water formation by Equation 4 and consumption by Equation 3 are equal, and the $\mathrm{H}_{2}$ pressure is stable, while $\mathrm{O}_{2}$ disappears at the rate characteristic of the $\mathrm{PuO}_{2}+\mathrm{H}_{2} \mathrm{O}$ reaction. 
The continuing decrease in pressure at a constant rate results from water-catalyzed oxidation of $\mathrm{PuO}_{2}$ by $\mathrm{O}_{2}$. Water produced by reaction of the $\mathrm{H}_{2}+\mathrm{O}_{2}$ mixture promotes the $\mathrm{PuO}_{2}+\mathrm{O}_{2}$ reaction according to the net process obtained by summing Equations 3 and 7 .

$$
\begin{gathered}
\mathrm{PuO}_{2}(\mathrm{~s})+\mathrm{xH}_{2} \mathrm{O} \text { (ads) } \rightarrow \mathrm{PuO}_{2+\mathrm{x}}(\mathrm{s})+\mathrm{x} \mathrm{H}_{2}(\mathrm{~g}) . \\
\mathrm{xH}_{2}(\mathrm{~g})+\mathrm{x} / 2 \mathrm{O}_{2}(\mathrm{~g}) \rightarrow \mathrm{xH}_{2} \mathrm{O} \text { (ads) } \\
\mathrm{PuO}_{2}(\mathrm{~s})+\mathrm{x} / 2 \mathrm{O}_{2}(\mathrm{~g}) \rightarrow \mathrm{PuO}_{2+\mathrm{x}}(\mathrm{s}) .
\end{gathered}
$$

The direct oxidation of $\mathrm{PuO}_{2}$ by $\mathrm{O}_{2}$ at $25^{\circ} \mathrm{C}$ is extremely slow, but occurs at the measurable rate of the $\mathrm{PuO}_{2}+\mathrm{H}_{2} \mathrm{O}$ reaction when moisture is present. The linear P-t curve observed beyond 70 days results from catalyzed reaction of oxygen via Equation 7 . Two catalytic processes work in concert as a cyclic process on the oxide surface. Water acts as a catalytic intermediate that accelerates the oxidation rate of $\mathrm{PuO}_{2}$, while the oxide surface regenerates $\mathrm{H}_{2} \mathrm{O}$ by catalyzing the combination of product hydrogen with oxygen.

\section{Physicochemical properties}

\subsection{Properties of metal-oxygen-hydrogen compounds}

The mechanism for moisture-enhanced corrosion of uranium and plutonium must be consistent with properties of potential products. This is important because all observations suggest that the corrosion rate is determined by the corrosion product(s) formed on the metal surface. Identification of the product layer is essential and consideration must be given to chemical, thermodynamic, structural, and transport properties of known compounds in the temary oxygen-hydrogen systems of the metals. Mechanisms that are inconsistent with known properties must be rejected.

Properties of binary uranium and plutonium oxides are extensively reviewed by Colmenares $[12,16]$. In air at temperatures between 25 and $500^{\circ} \mathrm{C}$, thermodynamically stable oxides of uranium form at composition extending from substiochiometric dioxide $\left(\mathrm{UO}_{2-\mathrm{x}}, \mathrm{x} \leq 0.006\right)$ to superstoichiometric dioxide $\left(\mathrm{UO}_{2+\mathrm{x}}, \mathrm{x}<0.20\right)$. At higher $\mathrm{O} / \mathrm{U}$ ratios, another phase of variable stiochiometry $\left(\mathrm{UO}_{2.25 \pm x}\right)$ forms near the $\mathrm{U}_{4} \mathrm{O}_{9}$ composition. Higher oxides are also stable, but are not observed during corrosion. The cited oxides have structures derived from that of fcc fluorite $\left(\mathrm{CaF}_{2}\right)$-type $\mathrm{UO}_{2}\left(\mathrm{a}_{0}=5.470 \AA\right)$, but their phase-boundary compositions are uncertain. Whereas $\mathrm{UO}_{2-\mathrm{x}}$ coexists with oxygen saturated metal and has a structure derived by formation of oxygen vacancies in the dioxide lattice, $\mathrm{UO}_{2+\mathrm{x}}$ forms under oxidizing conditions by incorporation of excess oxygen in $\propto$ ctahedral interstices of the fluorite structure. The bcc $\mathrm{U}_{4} \mathrm{O}_{9}$ phase $\left(\mathrm{a}_{0} \sim 21 \AA\right)$ is formed by longrange ordering of interstitial oxygen in the fluorite-related lattice. The $\mathrm{UO}_{2+\mathrm{x}}$ phase is an 
intrinsic p-type semiconductor. The diffusion coefficient (D) for oxygen self-diffusion is $10^{9}$ greater than that for uranium self-diffusion and increases with increasing $x$, a change consistent with a decrease in activation energy $\left(E_{2}\right)$ for oxygen diffusion from $250 \mathrm{~kJ} \mathrm{~mol}^{-1}$ $\left(70 \mathrm{kcal} \mathrm{mol}^{-1}\right)$ for $\mathrm{x}=0.001$ to $90 \mathrm{~kJ} \mathrm{~mol}^{-1}\left(23 \mathrm{kcal} \mathrm{mol}^{-1}\right)$ for $\mathrm{x}=0.02$ to 0.15 .

Extrapolation of data from high temperatures indicates that $\mathrm{D}$ for $\mathrm{UO}_{2.01}$ is $10^{20}$ larger than that for $\mathrm{UO}_{2.001}$ at $100^{\circ} \mathrm{C}$.

As outlined in discussing the interaction between plutonium dioxide and water, recent results $[7,8]$ show that the plutonium-oxygen system is significantly more complex than previously thought $[12,16]$. A low-composition oxide $\left(\alpha-\mathrm{Pu}_{2} \mathrm{O}_{3}\right)$ is formed by mild oxidation of clean metal or by auto-reduction of the dioxide layer on the metal under nonoxidizing conditions. This trivalent phase is nonstoichiometric with $\mathrm{Pu}_{2} \mathrm{O}_{3-x}$ and $\mathrm{Pu}_{2} \mathrm{O}_{3+x}$ coexisting with oxygen-saturated metal and substoichiometric dioxide, respectively. Behavior of the dioxide is remarkably similar to that of uranium. Whereas a substoichiometric phase $\left(\mathrm{PuO}_{2-\mathrm{x}}, \mathrm{x} \leq 0.02\right)$ is stable under reducing conditions at room temperature, $\mathrm{a} \mathrm{PuO}_{2+x}$ phase (maximum $\mathrm{x}>0.25$ ) is stable in air and other oxidizing atmospheres. Reaction of $\mathrm{PuO}_{2}$ reacts with dry oxygen is not observed, but $\mathrm{PuO}_{2+\mathrm{x}}$ is formed at a measurable rate by the reaction of water [8]. Structural relationships of the $\mathrm{PuO}_{2-\mathrm{x}}$ and $\mathrm{PuO}_{2+\mathrm{x}}$ to fluorite-type $\mathrm{PuO}_{2}\left(\mathrm{a}_{\mathrm{o}}=5.397 \AA\right)$ correspond to those for the uranium system. The structure of bcc $\mathrm{Pu}_{2} \mathrm{O}_{3}\left(\mathrm{a}_{0}=11.02 \AA\right)$ is derived by ordered removal of one one-fourth of oxygen from the $\mathrm{PuO}_{2}$ structure. Whereas $\mathrm{PuO}_{2}$ is a p-type semiconductor, electrical properties of $\mathrm{PuO}_{2+\pi}$ are unknown, but are expected to indicate p-type semiconduction like that of $\mathrm{UO}_{2-x}$. Data for oxygen self-diffusion in $\mathrm{PuO}_{2-\mathrm{x}}$ shows that $\mathrm{E}_{2}$ ranges from $95 \mathrm{~kJ} \mathrm{~mol}^{-1}\left(23 \mathrm{kcal} \mathrm{mol}^{-1}\right)$ to $190 \mathrm{~kJ} \mathrm{~mol}^{-1}\left(45 \mathrm{kcal} \mathrm{mol}^{-1}\right)$ [17]. These results are remarkably similar to those for $\mathrm{UO}_{2+\mathrm{x}}$ and suggest that measurements included compositions in the $\mathrm{PuO}_{2+\times}$ range, as well as with the stoichiometric dioxide.

Uranium and plutonium react with elemental hydrogen to form stable binary hydrides with somewhat dissimilar properties $[18,19]$. At $25^{\circ} \mathrm{C}$ and higher temperatures, $U$ forms $\beta$ - $\mathrm{UH}_{3}$, a metallic phase with an unusual cubic anti- $\mathrm{W}_{3} \mathrm{O}$ structure $\left(\mathrm{a}_{\mathrm{o}}=6.644 \AA\right)$. A substoichiometric $\mathrm{UH}_{3 \cdot x}$ phase formed by loss of hydrogen upon heating coexists with hydrogen-saturated metal. Equilibrium $\mathrm{H}_{2}$ pressures in the $\mathrm{U}_{-} \mathrm{UH}_{3-\mathrm{x}}$ two-phase region are $3 \mathrm{nbar}$ and $5 \mathrm{mbar}$ at 25 and $250^{\circ} \mathrm{C}$, respectively. Plutonium forms a metallic fcc fluoritetype $\mathrm{PuH}_{2}$ phase $\left(\mathrm{a}_{0}=5.359 \AA\right)$ that exhibits substantial substoichiometry upon heating. Hydrogen pressures in equilibrium with $\mathrm{Pu}+\mathrm{PuH}_{2-\mathrm{x}}$ are on the order of $10^{-21}$ bar and $3 \mu \mathrm{bar}$ at 25 and $250^{\circ} \mathrm{C}$, respectively. Increasing the hydrogen pressure results in facile formation 
of a $\mathrm{PuH}_{2+\mathrm{x}}(\mathrm{x} \leq 1)$ phase by accommodation of hydrogen in octahedral interstices of the fluorite structure, even at temperatures below $25^{\circ} \mathrm{C}$.

Oxide hydride phases are formed by reaction of plutonium with liquid water or nearneutral salt solutions [20]. The initial product is plutonium monoxide monohydride $(\mathrm{PuOH})$, a fluorite-related phase $\left(\mathrm{a}_{0}=5.401 \AA\right)$ in which anionic sites are equally occupied by oxygen and hydrogen. The fine black product reacts with water to form $\mathrm{Pu}_{7} \mathrm{O}_{9} \mathrm{H}_{3}$ and decomposes with loss of $\mathrm{H}_{2}$ when heated in vacuum at $120-200^{\circ} \mathrm{C}$. Oxide hydrides are not known for uranium.

\subsection{Chemistry of corrosion reactions}

Corrosion reactions of uranium and plutonium with dry air, water vapor, and moist air proceed with the formation of binary oxides $[2,4,12]$. Reaction of $U$ with dry air produces a superstoichiometric oxide with $x<0.25$.

$$
\mathrm{U}(\mathrm{s})+(2+\mathrm{x}) / 2 \mathrm{O}_{2}(\mathrm{~g}) \rightarrow \mathrm{UO}_{2+\mathrm{x}}(\mathrm{s})
$$

The corresponding reaction occurs for the reaction of Pu with dry oxygen, but $\mathrm{x}$ is essentially zero because of slow kinetics [8].

Binary oxide is also formed by the reaction of uranium with water vapor.

$$
\mathrm{U}(\mathrm{s})+(2+\mathrm{x}) \mathrm{H}_{2} \mathrm{O}(\mathrm{g}) \rightarrow \mathrm{UO}_{2+\mathrm{x}}(\mathrm{s})+(2+\mathrm{x}) \mathrm{H}_{2}(\mathrm{~g}) .
$$

Concurrent formation of oxide and small amounts of hydride at temperatures less than $100^{\circ} \mathrm{C}$ was suggested by early work $[21,22]$, but the presence of $\mathrm{UH}_{3}$ was not experimentally verified in either case. The thermal behavior of products containing bound hydrogen suggest the presence of an oxide hydride [23]. More recent studies agree that the product of the $\mathrm{U}+\mathrm{H}_{2} \mathrm{O}$ reaction is $\mathrm{UO}_{2+x}$ [24] or $\mathrm{UO}_{2}$ [25].

The product layer formed on plutonium during kinetic studies of the $\mathrm{Pu}+\mathrm{H}_{2} \mathrm{O}$ reaction at $250^{\circ} \mathrm{C}$ is well characterized [26]. Micrographic results show that metal was covered by an oxide layer (30-40 $\mu \mathrm{m}$ thickness) accounting for half of the measured oxidation and that $15-20 \%$ of the oxide-metal interface was occupied by inclusions of plutonium hydride. Estimation of the product ratio from the total extent of oxidation and the amount of hydride observed micrographically shows that the product fraction of $\mathrm{PuH}_{2}$ is approximately 0.15 , a value substantially less than the 0.67 fraction expected for stoichiometric reaction of water. Evidence for hydride formation is not found in products from kinetic studies at lower temperatures [4] and corrosion of plutonium by water vapor is best described by Equation 9.

Product formation during corrosion of uranium and plutonium in moist air or oxygen is described by Equations 8 and 9. However, as observed for the $\mathrm{Pu}+\mathrm{H}_{2} \mathrm{O}$ reaction at $250^{\circ} \mathrm{C}$, a small amount of hydride may accumulates at the oxide-metal interface as hydrogen- 
containing species diffuse through the oxide layer. That process is diminished by lowering the temperature and by removing product hydrogen from the reaction zone [24].

\subsection{General kinetic observations}

The reactions of uranium and plutonium with dry air, water vapor, and moist air have important kinetic features in common [12,16]. Freshly machined or burnished metal surfaces readily tarnish upon exposure to those atmospheres. Corrosion is most rapid initially and the rate progressively decreases over time as reaction proceeds and an increasingly thick layer of adherent product forms. After spallation of product begins, the corrosion rate becomes constant for a fixed temperature and reactant pressure. This process is described as "paralinear" because the extent of reaction follows a parabolic time dependence during the initial stage and a linear time dependence during the constant-rate stage. The behavior is characteristic of diffusion controlled processes in which the reaction rate is determined by the rate at which reactant diffuses through the product layer formed on the surface of a reactive material. The reaction rate slows as the layer thickness $(\tau)$ increases and becomes constant after continuing spallation of product particles and continuing oxidation establish a steady-state product layer of constant average thickness [2]. The linear stage is a constant-thickness variation of diffusion-controlled reaction with the same diffusion process occurring during both the parabolic and linear stages of corrosion.

Corrosion of product-coated uranium and plutonium in dry and humid atmospheres involves a sequence of steps common to product-throttled gas-solid reactions. Gaseous reactant reversibly adsorbs on the product surface at a concentration determined by the partial pressure of the reactant and the temperature. The adsorbed reactant dissociates to form atomic and ionic species. Dissociation and ion formation depend on ability of the product layer to transport electrons from the metal to the gas-solid interface. After entering the product lattice, the mobile species diffuses through the product layer and ultimately reacts at the product-metal interface to form solid product, electrons, and heat. The corrosion rate is determined by the rate at which the diffusing species is transported from the gas-solid interface to product-metal interface.

The relationship between the rates of corrosion and diffusion is formalized using a onedimensional model for diffusion. The rates of transport and reaction are defined by the flux (J) of the diffusing species.

$$
J=c D(d C / d \tau)
$$


$D$ is the temperature-dependent diffusion coefficient of the migrating species in the product, $\mathrm{dC} / \mathrm{d} \tau$ is the gradient in reactant concentration $C$ across the layer, and $\mathrm{c}$ is a proportionality constant. At constant temperature and $\tau, J$ depends only on $\mathrm{dC}$, the difference in reactant concentration across the diffusion barrier. If the reactant pressure is constant, $\mathrm{dC}$ and $\mathrm{J}$ are fixed and the corrosion rate is constant.

\section{Evaluation of proposed mechanisms}

Elements of the general process for product-throttled reaction appear in published mechanisms for moisture-enhanced corrosion of uranium. Proposed mechanisms consistently involve formation of an oxide diffusion layer and transport of reactant across that layer. Two primary methods for rate enhancement in the presence of moisture are proposed: (1) disruption of the protective oxide layer by formation of hydride at the product-metal interface and (2) more rapid transport of a chemical species other than oxygen. Both approaches require diffusion of a hydrogen containing species through the oxide layer. We outline these mechanisms and examine their consistency with material properties and kinetic behavior.

In some reports, the accelerated corrosion rate in moist air is attributed to mechanical disruption of the coherent oxide diffusion layer by formation of hydride at the oxide-metal interface [27]. This approach is proposed in an early report by Wilkinson [28]. According to this mechanism, small amount of $\mathrm{H}^{+}$formed by autoionization of adsorbed $\mathrm{H}_{2} \mathrm{O}$ diffuses through the oxide layer and forms $\mathrm{UH}_{3}$ or hydrogen gas, products that disrupt the protective oxide layer and "cause the rate of oxidation to increase and become linear." The fate of $\mathrm{OH}^{-}$remaining on the oxide surface is not specified. A similar mechanism proposed by Kondo et al. [22] also attributes moisture-enhancement to fracture of the protective oxide layer by stresses associated with hydride formation at the oxide-metal interface. Penetration of the oxide layer by $\mathrm{H}_{2} \mathrm{O}$ apparently results in fornation of $\mathrm{UO}_{2+x}, \mathrm{UH}_{3 \cdot x}$, and H. Atomic hydrogen returns to the gas-solid interface and reacts with $\mathrm{O}_{2}$ to form $\mathrm{H}_{2} \mathrm{O}$. Cracking of the oxide layer reactivates the formation of oxide and hydride in a stage "observed as a linear rate law." The basis for linear kinetics and the fate of hydride and hydrogen are not specified for these mechanisms.

Alternative enhancement mechanisms involve diffusion of hydroxide through the oxide layer. MCD. Baker et al.[29] account for results of isotopic-exchange studies in which labeled oxygen $\left(\mathrm{O}_{2}{ }^{*}\right)$ was transformed into $\mathrm{H}_{2} \mathrm{O}^{*}$ during corrosion of $\mathrm{U}$ by moist oxygen. Diffusion of $\mathrm{OH}$ ions formed by autoionization of water at the gas-oxide interface results in formation of $\mathrm{UO}_{2}$ and $\mathrm{H}$ atoms at the oxide-metal interface. Atomic hydrogen diffuses 
back to the gas-solid interface and forms water by reacting with neutral $\mathrm{OH}$ produced by surface reaction of $\mathrm{H}^{+}$with $\mathrm{O}_{2}$ and electrons. The origin of linear oxidation kinetics is not addressed. Colmenares $[12,30]$ attributes the enhanced rate of $\mathrm{U}+\mathrm{H}_{2} \mathrm{O}$ corrosion to more rapid diffusion of $\mathrm{OH}^{-}$formed by dissociative chemisorption of $\mathrm{H}_{2} \mathrm{O}$ on $\mathrm{UO}_{2}$. Reaction of $\mathrm{OH}^{-}$at the oxide-metal interface produces $\mathrm{UO}_{2}$ and $\mathrm{H}^{+}$, a species that diffuses back to the gas-oxide interface, reacts with electrons, and associates to form $\mathrm{H}_{2}$. Linear kinetics are interpreted as implying that "oxidation is independent of oxide thickness." Similar mechanisms involving diffusion of $\mathrm{OH}^{\circ}[31]$ and both $\mathrm{OH}^{\circ}$ and $\mathrm{O}^{2-}[32]$ are also proposed for oxidation in moist air.

Mechanisms proposed for enhanced corrosion of plutonium in water vapor are similar to those for uranium. The mechanism suggested by Thompson [33] involves reaction of water with metal to form $\mathrm{PuO}_{2}$ and $\mathrm{PuH}_{2}$, a product that reacts with water to form oxide at an accelerated rate and is reformed by reaction of the $\mathrm{H}_{2}$ product with metal. Hydroxide phases appear as intermediates in the accelerated reaction. A rather complicated mechanism proposed by Waber [34] involves autoionization of water, diffusion of $\mathrm{OH}^{-}$to the oxidemetal interface, and appearance of $\mathrm{Pu}(\mathrm{OH})_{3}$ and $\mathrm{Pu}(\mathrm{OH})_{4}$ intermediates prior to formation $\mathrm{PuO}_{2}$ plus $\mathrm{H}_{2} \mathrm{O} . \mathrm{H}_{2}$ is produced by association of $\mathrm{H}^{+}$with electrons at the surface, but the fate of the water formed at the oxide-metal interface is unclear.

A common feature of the mechanisms proposed for both metals is the diffusion hydrogen $\left(\mathrm{H}^{+}\right)$or a hydrogen containing species $\left(\mathrm{H}_{2} \mathrm{O}\right.$ or $\left.\mathrm{OH}\right)$ to the oxide-metal interface. In most cases, all or part of the hydrogen returns to the gas-oxide interface for involvement in further reaction. As shown by the low equilibrium hydrogen pressures for the metalhydride two-phase region below $250^{\circ} \mathrm{C}$ (Section 4.1), all hydrogen that reaches the oxidemetal interface remains as $\mathrm{UH}_{3}$ or $\mathrm{PuH}_{2}$. Retention of hydrogen as hydride at the oxidemetal interface is demonstrated by experimental data showing that reaction of hydridecoated ( $100 \mu \mathrm{m}$-thick $\mathrm{PuH}_{2}$ ) plutonium with oxygen completely consumes the metal without forming $\mathrm{H}_{2}$ [3]. Hydrogen formed by advancement of the oxidation front progressively moves inward by reforming hydride and is quantitatively present as a $\mathrm{PuH}_{3+x}$ core inside a thick layer of oxide when reaction ceases, even though autothermic temperatures exceed $1000^{\circ} \mathrm{C}$. Transport of $\mathrm{OH}^{\circ}$ or $\mathrm{H}_{2} \mathrm{O}$ to the oxide-metal interface will form a product layer containing $40-56 \% \mathrm{UH}_{3}$ or $50-67 \% \mathrm{PuH}_{2}$. If correct, reactions defined by mechanisms outlined above must result in formation product mixtures containing such large fractions of hydride. Experimental data show that binary oxides are the only solid products formed during corrosion of metals in moist conditions. Therefore, 
all mechanisms involving formation of hydride or transport of hydrogen-containing species are inconsistent with the fundamental chemistry of corrosion and must be invalid.

A mechanism that does not involve hydride formation or transport of hydrogencontaining species is suggested by Colmenares for oxidation of uranium in moist air [12]. Adsorption of $\mathrm{O}_{2}$ and diffusion of $\mathrm{O}^{2}$ through the oxide layer is proposed to account for the observed dependence of rate on water pressure. This procesis appears identical to that for oxidation of uranium in dry air and the source of rate enhancement by moisture is not evident. An alternative possibility involves diffusion of $\mathrm{O}^{-}$formed by dissociation of $\mathrm{OH}$, a species produced at the gas-oxide interface by chemisorption of water on $\mathrm{UO}_{2}$. This process forms $\mathrm{H}_{2}$, a product is not observed during corrosion of uranium in moist air.

We conclude that a fresh approach is needed to develop consistent and comprehensive mechanisms for corrosion of uranium and plutonium in dry air, water vapor, and humid air. As detailed in the following section, experimental results from the present study play a key role in this effort. The examination of kinetic behavior is confined to the parametric range of the temperature-humidity envelopes of the metals and is generally bounded by temperatures of $25-250^{\circ} \mathrm{C}$ and oxidant pressures up to 160 torr for oxygen and saturation pressures for water vapor.

\section{The mechanistic concept}

Relevant kinetic and chemical features of moisture enhanced corrosion of uranium and plutonium emerge from the preceding discussion and from prior reports on the chemical and kinetic behavior of uranium and plutonium $[2,4]$. The time dependence of corrosion in dry air, water vapor, and moist air indicate that the rates of these reactions are controlled by diffusion of reactant through a coherent oxide layer on the metal surface. In each case, the corrosion rate becomes constant after a steady-state thickness of oxide is established. As shown by the Equation 11, the flux of reactant diffusing through a layer at fixed $\tau$ and $T$ is determined by $\mathrm{dC}$. Using this concept, we define a single diffusion process that accounts for behavior at all conditions.

The comprehensive mechanism for enhanced corrosion of uranium and plutonium is based on a single diffusion process and on occurrence of surface reactions that alter the gradient in oxygen concentration across the oxide diffusion banrier in different atmospheres. Its development progresses systematically from the basic mechanism for oxidation in dry air, to that for corrosion in water vapor, and ultimately to that for corrosion in moist air. As implied by parabolic behavior and Equation 9, the fundamental rate- 
controlling process is diffusion of $\mathrm{O}^{2-}$ through the layer of oxide formed on the metal during corrosion.

Rate enhancement in water vapor is attributed to an increase in the $\mathrm{O}^{2 \cdot}$ gradient by chemisorption of water as $\mathrm{OH}^{\circ}$ on the oxide and to facilitation of oxide ion formation. Association of $\mathrm{OH}^{-}$with an electron forms $\mathrm{O}^{2}$ and $\mathrm{H}$, a product that associates and desorbs as $\mathrm{H}_{2}$. The fundamental diffusion and enhancement processes are also preserved during corrosion in moist air, but the surface chemistry is altered by the catalytic nature of the oxide surface. Hydrogen atoms produced during formation of $\mathrm{O}^{2-}$ at the gas-oxide interface interact with adsorbed and dissociated oxygen to reform water. The $\mathrm{H}_{2} \mathrm{O}$ concentration remains constant, $\mathrm{H}_{2}$ is not formed, and $\mathrm{O}_{2}$ reacts at an accelerated rate. Chemisorbed water is ultimately unstable at elevated temperatures and desorption of water results in loss of moisture enhanced kinetics.

We develop this mechanistic concept in the following section of this report and establish its consistency with properties of the oxide corrosion product, kinetic results, and other experimental observations. Kinetic behavior is determined solely by interaction of oxidants with the oxide layer. Except for the electropositive nature that drives oxide formation, properties of uranium and plutonium do not alter the corrosion kinetics.

\section{A comprehensive corrosion mechanism}

\subsection{Corrosion in dry air}

\subsubsection{Chemistry and oxide properties in dry air}

At temperatures of interest, oxides are the only products formed by atmospheric corrosion of uranium and plutonium. Uranium also reacts with elemental nitrogen at elevated temperatures, but similar behavior is not observed for plutonium [2]. Differences are also observed in compositions of the adherent oxide layers. High-composition oxide is readily formed by reaction of $\mathrm{UO}_{2}$, but the composition of the oxide layer varies continuously from $\mathrm{UO}_{2+x}$ at the surface to $\mathrm{UO}_{2-x}$ at the oxide-metal interface. The $\mathrm{PuO}_{2+x}$ phase is not observed in dry conditions, but the composition of the oxide layer varies from $\mathrm{PuO}_{2}$ to $\mathrm{Pu}_{2} \mathrm{O}_{3-x}$ across the oxide layer. A phase boundary exists at the $\mathrm{PuO}_{2-x}-\mathrm{Pu}_{2} \mathrm{O}_{3+x}$ interface, but the fluorite-related lattices are coherent and the layer is not disrupted by severe structural discontinuity. Particles of both oxides continue to react after spallation and only high-composition oxides are indicated by analysis of those products.

The fundamental nature of the oxide layer and associated mechanistic constraints are discussed in the early work by Wilkinson [28]. The oxide must be able to transport oxygen from the gas-oxide interface to the oxide metal interface and to move electrons in 
the opposite direction. Mass transport is limited to diffusion of charged species because the mobility of neutral atoms and molecules is insignificant in oxide. Departure from ideal oxide stoichiometry by formation of oxygen interstitials or vacancies is necessary for the existence of a concentration gradient across the oxide layer. Semiconduction in the oxides is most consistent with a diffusion-like process involving hopping of electrons (or holes) between neighboring cations such as U(IV)-U(V) and Pu(III)-Pu(IV) in the lattice [16]. Transport requirements for uranium and plutonium oxides are satisfied by their behavior as ionic conductors and intrinsic semiconductors [12].

\subsubsection{Kinetic behavior in dry air}

Existence of a paralinear time dependence for oxidation in dry air is demonstrated for both uranium [27] and plutonium [5]. As discussed in Section 4.3, this behavior establishes a basis for concluding that an isothermal and isobaric reaction proceeds at a constant rate while remaining under diffusion control. The same diffusion process that occurs during the parabolic stage continues as simultaneous oxide spallation and oxidation maintain a product layer of constant average thickness on the metal surface.

The temperature dependence of oxidation is consistent with a diffusion-controlled reaction involving transport of oxygen through the oxide. The $\mathrm{E}_{\mathrm{a}}$ values of $67 \mathrm{~kJ} \mathrm{~mol}^{-1}$ $\left(16 \mathrm{kcal} \mathrm{mol}^{-1}\right)$ for oxidation of uranium [31] and $79 \mathrm{~kJ} \mathrm{~mol}^{-1}\left(19 \mathrm{kcal} \mathrm{mol}^{-1}\right)$ for oxidation of plutonium [3] during the linear stage are in good agreement with the value of $95 \mathrm{~kJ} \mathrm{~mol}^{-1}$ $\left(23 \mathrm{kcal} \mathrm{mol}^{-1}\right.$ ) measured for oxygen self-diffusion in both $\mathrm{UO}_{2+x}$ and $\mathrm{PuO}_{2-x_{-}^{-}}$Precise agreement is not expected because the oxygen transport rate is sensitive to temperaturedependent factors other than the diffusion coefficient. Experimental observations show that the steady-state thickness of adherent oxide on plutonium increases with temperature from about $4 \mu \mathrm{m}$ at $25^{\circ} \mathrm{C}$ to more than $30 \mu \mathrm{m}$ at $250^{\circ} \mathrm{C}$ [35] and similar behavior is expected for uranium. Stoichiometry limits of the equilibrium oxides at the gas and metal interfaces of the oxide layer also vary with temperature. The potential effects of temperature are especially significant for plutonium because the fraction of $\mathrm{PuO}_{2-\mathrm{x}}$ in the oxide layer decreases from almost 1.0 at $25^{\circ} \mathrm{C}$ to a minor value as the rate of the metal-oxide autoreduction reaction increases sharply with temperature [35]. This composition shift greatly increases the concentration of oxygen vacancies in the oxide, a change that tends to lower the activation energy for diffusion [12]. Observation of pressure-dependent oxidation rates shows that the oxide surface is not saturated by adsorbed $\mathrm{O}_{2}$ and implies that increasing the temperature at constant pressure reduces the adsorbate concentration and the oxygenconcentration gradient across the layer. 
The dependence of oxidation rate on oxygen pressure is modest and of similar magnitude for both uranium [12] and plutonium [36]. The oxidation rates are proportional to $\mathrm{P}\left(\mathrm{O}_{2}\right)^{\mathrm{m}}$ with values of $m$ ranging form 0.1 to 0.4 for $U$ and from near zero to 0.5 for plutonium as temperature and pressure are varied. Colmenares relates corrosion kinetics to the oxygen transport process by demonstrating a proportionality between the oxidation rate and the electrical conductivity [12]. This relationship permits correlation of the measured pressure dependence for oxidation with that for electrical conductivity of known oxide compositions. Results obtained from theoretical models relating conductivity to the type of intrinsic defect in $\mathrm{UO}_{2+\mathrm{x}}$ show that low values of $m$ observed near $120^{\circ} \mathrm{C}$ correspond to formation of doubly ionized clusters by association of interstitial (octahedral sites in the fluorite structure) $\mathrm{O}^{2}$ ions with positive holes created by the presence of $U(V)$ on normal cation sites in the metal lattice composed predominately of U(IV) ions. Values of $m$ near 0.4 suggest that transport at higher temperatures may include a contribution from singly ionized clusters formed by interstitial $\mathrm{O}^{-}$ions and holes. As electrons move toward the gasoxide interface, anionic clusters formed by positive holes and oxide anions move toward the oxide-metal interface in a concerted process consistent with the relationship between rate and conductivity. It is apparent that $\mathrm{O}^{2}$ ions are the only diffusing species in the $\mathrm{UO}_{2+x}$ lattice.

The defect clusters formed in during uranium oxidation have unique positron annihilation lifetimes $[12,24]$. The characteristic lifetime of the doubly ionized interstitial cluster formed in $\mathrm{UO}_{2+\pi}$ during oxidation at dry conditions is near or above $400 \mathrm{ps}$. This lifetime distinguishes the oxide product from oxides having other defect clusters, as well as from $\mathrm{U}$ and $\mathrm{UH}_{3}$.

\subsubsection{An mechanism for oxidation in dry air}

Formulation of the oxidation mechanism for oxidation of uranium and plutonium in dry air is based on the following observations: (1) Compositions in the oxides depart from stiochiometry and allow for establishment of concentration gradients across the product layers. (2) The time dependence of the extent of oxidation is paralinear, indicating that the process is controlled by diffusion of reactant through the oxide layer and that linear kinetics appear at constant $\mathrm{T}$ and $\mathrm{PO}_{2}$ after a steady-state oxide layer of constant average thickness is attained. (3) The temperature dependence of the reaction agrees with that for oxygen self-diffusion in the oxide. (4) The pressure dependence of oxidation correlates with formation of interstitial clusters that carry $\mathrm{O}^{2-}$ toward the oxide-metal as electrons simultaneously move toward the gas-oxide interface.

The initial mechanistic step is dissociative adsorption of $\mathrm{O}_{2}$ at the gas-oxide interface. 


$$
\mathrm{O}_{2}(\mathrm{~g}) \leftrightarrow \mathrm{O}_{2} \text { (ads) } \leftrightarrow 2 \mathrm{O} \text { (ads) . }
$$

This reversible process is followed by interaction of atomic oxygen with electrons to form $\mathrm{O}^{2}$ ions and $\mathrm{U}(\mathrm{V})$ holes, products that associate to form defect clusters.

$$
2 \mathrm{O}(\mathrm{ads})+4 \mathrm{e}^{-} \rightarrow 2 \mathrm{O}^{2-} \text { (ads) } \rightarrow 2 \mathrm{O}^{2-} \text { (lat) } .
$$

The rate of $\mathrm{O}^{2-}$ formation via Equation 13 is important in determining the concentration of the diffusing species at the oxide surface. Conceptually, this process is determined by the surface concentration of $O$ and by transfer of two electrons to each oxygen. This transfer most likely occurs by two sequential one-electron steps instead of a single and highly improbable two-electron process. The concentration of $\mathrm{O}^{2-}$ at the surface is a steady-state value established by the rates of ion formation and diffusion through the oxide lattice. Entry of $\mathrm{O}^{2-}$ into the lattice is facilitated by concurrent formation of two positive holes at the oxide surface during electron transfer. Transport of $\mathrm{O}^{2-}$ occurs by nigration of clusters to the gas-oxide interface via the concerted process involving countercurrent movement of electrons. After reaching the oxide-metal interface, oxide ions react to form dioxide and electrons that neutralize the positive holes of the cluster.

$$
\mathrm{U}(\mathrm{Pu})(\mathrm{s})+2 \mathrm{O}^{2-} \text { (lat) } \rightarrow \mathrm{UO}_{2}\left(\mathrm{PuO}_{2}\right)(\mathrm{s})+4 \mathrm{e}^{-} .
$$

Summation of Equations 12-14 yields Equation 9, the net chemical reaction for corrosion of the metal in dry air.

\subsection{Corrosion in water vapor}

\subsubsection{Chemistry and oxide properties in water vapor}

As outlined in the preceding discussion, uranium and plutonium react with water to form $\mathrm{H}_{2}$, as well as $\mathrm{UO}_{2+\mathrm{x}}$ or $\mathrm{PuO}_{2+\mathrm{x}}$ as end products. Corrosion rates are markedly faster than observed for dry air. Formation of $\mathrm{PuO}_{2+x}$ and $\mathrm{H}_{2}$ by the $\mathrm{PuO}_{2}+\mathrm{H}_{2}$ Oreaction demonstrates that metal is only involved as an oxygen sink. As discussed in Section 7.1.1, oxide layers formed on the metals have continuously varying compositions. However, experimental data show that the oxide existing on plutonium during reaction of water vapor is more complex that formed in dry conditions and is composed of successive layers that vary in composition from $\mathrm{PuO}_{2+\mathrm{x}}$ at the gas-oxide interface to $\mathrm{Pu}_{2} \mathrm{O}_{3 \pm x}$ at the oxide-metal interface [26]. This observation provides direct evidence for rate control by diffusion through the product layer because one side of the oxide layer is in equilibrium with the gas phase and the other side is in equilibrium with the metal. This situation exists because the equilibrium regions are separated by the slow step of the reaction.

Results of this study and earlier work $[8,11]$ show that plutonium dioxide interacts strongly with water via two processes. Water chemisorbs dissociatively as $\mathrm{OH}^{\circ}$ on the 
$\mathrm{PuO}_{2}$ surface at room temperature and additional chemisorption is observed near $100^{\circ} \mathrm{C}$. Desorption occurs reversibly at $150^{\circ} \mathrm{C}$. Formation of the higher oxide and hydrogen is the only process observed at $250^{\circ} \mathrm{C}$. Formation of $\mathrm{PuO}_{2+\mathrm{x}}$ is thermodynamically favored and occurs at all temperatures in $25-35.0^{\circ} \mathrm{C}$ ran range, but the kinetically favored adsorption reaction is the dominant interaction at low temperatures. Results of thermodynamic calculations by Colmenares show that dissociative adsorption of water on $\mathrm{UO}_{2}$ is energetically favorable [24], and simultaneous occurrence of chemisorption and oxidation reactions is expected during exposure of $\mathrm{UO}_{2}$ to water vapor.

The appearance of hydride as a minor constituent in the corrosion products for both metals is significant. Small amounts of hydride are formed with static systems in which $\mathrm{H}_{2}$ accumulates, but is not seen if the gaseous product is swept away [12]. Hydride appears at the oxide-metal interface during extended reaction of water at elevated temperatures as trace amounts of hydrogen migrate through the oxide via secondary diffusion processes involving $\mathrm{OH}^{*}$ or $\mathrm{H}^{+}$. Hydride stability is demonstrated by its formation. The low fractions of hydride in the products formed by water shows that the mechanism for oxidation by water vapor does not involve transport of $\mathrm{OH}^{\circ}$ or any other hydrogencontaining species to the oxide-metal interface. Therefore, $\mathrm{O}^{2-}$ must also be the only diffusing species in oxide formed by water vapor. This conclusion is supported by results of positron annihilation measurements showing that the defect lifetime observed for oxide formed by the $\mathrm{U}+\mathrm{H}_{2} \mathrm{O}$ reaction is $425 \mathrm{ps}$ and that the same doubly ionized cluster associated with oxidation in dry oxygen is present in the oxide formed by water [12,24]

\subsubsection{Kinetic behavior in water vapor}

Paralinear time dependence is observed for the reaction of plutonium [37] with water vapor. This result does not agree with the reported observation of linear kinetics for the $\mathrm{U}+\mathrm{H}_{2} \mathrm{O}$ reaction and with the conclusion that oxidation is independent of oxide thickness [12]. According to that report, spallation of uranium oxide begins when the oxide thickness reaches about $1 \mu \mathrm{m}$, a value consistent with data for plutonium [35] and corresponding to a total mass gain of $0.10-0.15 \mathrm{mg} \mathrm{cm}^{-2}$ during the parabolic step. Except for a single measurement, mass-time data presented in the report and in a referenced source [24] are for mass gains of $1 \mathrm{mg} \mathrm{cm}^{-2}$ or greater. However, interferometric measurements during reaction of $U$ with $\mathrm{H}_{2} \mathrm{O}$ vapor at 20 torr and $30-80^{\circ} \mathrm{C}$ show that the initial stage of reaction is essentially parabolic [38,39]. Preference is given to the more-sensitive measurements. Existence of paralinear kinetics during reaction of $\mathrm{H}_{2} \mathrm{O}$ is consistent with formation of oxide by water and with positron the annihilation results cited above. 
Observations imply that the diffusion process occurring during reaction of water vapor is identical to that occurring during reaction of dry air.

As indicated by activation energies of $54 \mathrm{~kJ} \mathrm{~mol}^{-1}\left(14 \mathrm{kcal} \mathrm{mol}^{-1}\right)$ for the $\mathrm{U}+\mathrm{H}_{2} \mathrm{O}$ reaction and $141 \mathrm{~kJ} \mathrm{~mol}^{-1}\left(34 \mathrm{kcal} \mathrm{mol}^{-1}\right)$ for the $\mathrm{Pu}+\mathrm{H}_{2} \mathrm{O}$ reaction, the temperature dependence for uranium is similar to that for dry air, whereas that for plutonium is significantly higher. The noticeable increase for $\mathrm{Pu}$ is attributed to rate enhancement from adsorption of additional water, not to a change in the diffusion process. The increase in corrosion rate with temperature is consistent with the increase in concentration of adsorbed water with temperature observed in this study. However, an equally significant temperature effect for both metals is the convergence of water vapor and dry air at elevated temperatures. For plutonium, this convergence is accompanied by a sharp decrease in rate at $110-200^{\circ} \mathrm{C}[3,4]$, the temperature range in which $\mathrm{H}_{2} \mathrm{O}$ thermally desorbs from oxide in the presence of water vapor. Closure of the temperature-humidity envelope for uranium is apparently driven by a similar desorption process [2]. Behavior implies that rate enhancement by water vapor results from the high surface concentration of oxygen present as adsorbed hydroxide.

Observation of a square-root dependence of the corrosion rate on water pressure for both uranium [2] and plutonium [4] also indicates that the enhanced corrosion rate is related to adsorption of water. As noted by Stakebake [36], this dependence implies that corrosion rate is proportional to the concentration of hydroxide, $[\mathrm{OH}]$, adsorbed on the oxide surface. The relationship of $\left[\mathrm{OH}^{-}\right]$to water pressure is defined by the equilibrium constant for adsorption according to the net process defined by Equations 1 and 2.

$$
\mathrm{K}=\left(\left[\mathrm{OH}^{-}\right]^{2}\right) /\left(\left[\mathrm{O}^{2}\right] \mathrm{P}\left(\mathrm{H}_{2} \mathrm{O}\right)\right) \text {. }
$$

Since the concentration of $\mathrm{O}^{2-}$ in the lattice is constant, $\left[\mathrm{OH}^{-}\right]$is proportional to $\mathrm{P}\left(\mathrm{H}_{2} \mathrm{O}\right)^{1 / 2}$. Therefore, if the corrosion rate is proportional to $\left[\mathrm{OH}^{-}\right]$, it is expected to vary as $\mathrm{P}\left(\mathrm{H}_{2} \mathrm{O}\right)^{1 / 2}$. Experimental observation of this dependence strongly supports the conclusion that enhancement of the oxidation rates for uranium and plutonium in water vapor results from an increase in the surface concentration of oxygen by adsorption of $\mathrm{H}_{2} \mathrm{O}$ as $\mathrm{OH}$.

\subsubsection{A mechanism for oxidation in water vapor}

The proposed mechanism for reaction of uranium and plutonium with water vapor is based on the following observations: (1) Corrosion of the netals by water vapor proceeds with formation of oxide and $\mathrm{H}_{2}$. (2) The oxide products formed by reaction of $\mathrm{H}_{2} \mathrm{O}$ are essentially identical to those formed on dry air. (3) The time dependence of oxidation is paralinear for both metals and suggests that an oxide diffusion barrier of constant thickness is present during the linear stage. (4) Water chemisorbs as hydroxide on the oxide in the 
low-temperature range where rate enhancement is observed and desorbs at high temperatures where rate enhancement terminates. (4) The square-root dependence on water pressure implies that the corrosion rate is proportional to the surface concentration of hydroxide. (5) The oxidation mechanism is constrained by thermodynamic and chemical properties that preclude transport of $\mathrm{OH}^{-}$to the oxide-metal interface.

Except for the reactions involved in $\mathrm{O}^{2}$ - formation at the gas-oxide interface, oxidation of uranium and plutonium proceeds via the same mechanism as oxidation in air. During the initial step, water adsorbs on the oxide and reacts with oxide ions in the lattice to form hydroxide as described by Equations 1 and 2. Association of $\mathrm{OH}^{-}$with an electron forms an $\mathrm{O}^{2-}$ ion and an $\mathrm{H}$ atom.

$$
2 \mathrm{OH}^{-} \text {(ads) }+2 \mathrm{e}^{\circ} \rightarrow 2 \mathrm{O}^{2-} \text { (lat) }+2 \mathrm{H} \text { (ads) } .
$$

Half of the $\mathrm{O}^{2-}$ ions formed by this reaction occupy the vacant anion sites created during formation of $\mathrm{OH}$ ions by Equation 2. The remaining ions enter interstitial sites and associate with positive holes to form defect clusters that diffuse to the oxide-metal interface and react as described by Equation 14. Association of adsorbed $\mathrm{H}$ atoms results in formation and desorption of $\mathrm{H}_{2}$.

$$
2 \mathrm{H} \text { (ads) } \rightarrow \mathrm{H}_{2} \text { (ads) } \rightarrow \mathrm{H}_{2} \text { (g) } .
$$

Enhancement of the oxidation rate in water vapor is driven by an increase in the oxide ion concentration at the gas-oxide interface. Formation of $\mathrm{O}^{2-}$ is facilitated by a high $[\mathrm{OH}]$ at the oxide surface and by the transfer of a single electron during the reaction. The rate of reaction is rapid compared to the equivalent process for oxidation in dry air. That reaction is relatively slow because the oxygen concentration is comparatively low and the transfer of two electrons is has low probability. The observed proportionality between corrosion rate in water vapor and concentration of adsorbed hydroxide is a consequence of Equation 17. The oxidation rate is enhanced because increasing the $[\mathrm{OH}]$ by adsorption of water increases the $\mathrm{O}^{2}$ concentration at the surface and the concentration gradient across the constant-thickness oxide layer. The $[\mathrm{OH}]$ is decreased by thermal desorption of water at elevated temperatures. The resulting drop in $\mathrm{O}^{2}$ concentration is mirrored in a slowed corrosion rate and in ultimate disappearance of moisture enhancement.

\subsection{Corrosion in moist air}

\subsubsection{Chemistry and oxide properties in moist air}

The oxides formed by the reactions of uranium and plutonium in moist air are indistinguishable from those formed in dry air or water vapor, but the chemical behavior is complex. The unusual behavior of gaseous species during corrosion of a 1.5:1.0 molar mixture of $\mathrm{O}_{2}$ and $\mathrm{H}_{2} \mathrm{O}$ is shown by results from a study by $\mathrm{McD}$. Baker et al. in Figure 3 
[29]. The $\mathrm{O}_{2}$ concentration decreases linearly to zero at an accelerated rate, while the concentration of $\mathrm{H}_{2} \mathrm{O}$ remains constant and only a trace of $\mathrm{H}_{2}$ appears. After $\mathrm{O}_{2}$ is depleted, reaction of $\mathrm{H}_{2} \mathrm{O}$ is accompanied by formation of $\mathrm{H}_{2}$. Results of a complementary study by Kondo et al. show that the $\mathrm{U}_{+} \mathrm{H}_{2} \mathrm{O}$ reaction proceeds with formation of $\mathrm{H}_{2}$ at a linear rate until a quantity of $\mathrm{O}_{2}$ is injected into the system [22]. Formation of $\mathrm{H}_{2}$ ceases at that point and resumes at the initial linear rate after $\mathrm{O}_{2}$ is consumed.

Similar behavior is reported for corrosion of plutonium by moist air in a closed system. Oxygen reacts at a constant accelerated rate characteristic of the $\mathrm{Pu}+\mathrm{H}_{2} \mathrm{O}$ reaction, but $\mathrm{H}_{2}$ is not observed as a product [4]. The corrosion chemistry of both metals closely parallels that observed for the oxidation of $\mathrm{PuO}_{2}$ by moist $\mathrm{O}_{2}$ in this study. As $\mathrm{O}_{2}$ is consumed at the accelerated rate of the $\mathrm{Pu}+\mathrm{H}_{2} \mathrm{O}$ reaction, the $\mathrm{H}_{2} \mathrm{O}$ concentration remains constant and $\mathrm{H}_{2}$ is not formed.

Isotopic exchange studies by McD. Baker et al. show that complete reaction of ${ }^{18} \mathrm{O}_{2}$ (indicated by $\mathrm{O}^{*}$ ) during corrosion of uranium by $\mathrm{a}_{2} \mathrm{O}_{+} \mathrm{O}_{2}{ }^{*}$ mixture at $100^{\circ} \mathrm{C}$ results in formation of high-purity $\mathrm{H}_{2} \mathrm{O}^{*}$ and incorporation of $\mathrm{O}^{*}$ in the oxide product [29]. Purity of the $\mathrm{O}_{2}{ }^{*}$ is preserved during the reaction. Although a later study raises questions about these results [40], incorporation of oxygen from $\mathrm{O}_{2}{ }^{*}$ is confirmed by measurements involving isotopic labeling and depth-profile characterization of products formed by reaction of $\mathrm{U}$ with $\mathrm{H}_{2} \mathrm{O}, \mathrm{H}_{2} \mathrm{O}, \mathrm{H}_{2} \mathrm{O}+\mathrm{O}_{2}$ mixtures, and $\mathrm{H}_{2} \mathrm{O}+\mathrm{O}_{2} *$ mixtures [32]. Results are consistent with diffusion of oxygen through a preexisting $\mathrm{UO}_{2+x}$ layer that formed on the metal prior to testing and remained stationary during subsequent reaction. Profiles of products formed by $\mathrm{H}_{2} \mathrm{O}^{*}$ show that labeled oxide formed beneath this layer contains a constant $\mathrm{O}^{*}$ content of about $85 \%$. Profiles of oxides formed by reaction of $\mathrm{H}_{2} \mathrm{O}^{*}+\mathrm{O}_{2}$ mixtures show that the outer layer of unlabeled oxide was followed by oxide containing 70$80 \% \mathrm{O}^{*}$ and that the $\mathrm{O}^{*}$ percentage decreased with increasing depth. Conversely, the content of unlabeled $\mathrm{O}$ in the oxide formed by $\mathrm{H}_{2} \mathrm{O} \mathrm{O}_{2}{ }^{*}$ mixtures was about $90 \%$ near the surface, but decreased relative to $\mathrm{O}^{*}$ with increasing depth.

The depth-profile results provide direct evidence for diffusion of oxygen via an interstitial process. As evidenced by the stationary layer of unlabeled oxide at the surface, oxygen on the normal (tetrahedral) sites of the fluorite structure are immobile. Formation of an $\mathrm{O}^{*}$-rich layer beneath this oxide by reaction of $\mathrm{H}_{2} \mathrm{O}^{*}$ demonstrates that transport of oxygen to the oxide-metal interface occurs via interstitial (octahedral) sites in a process consistent with formation of anionic defect clusters.

Catalytic activity is an important chemical property of the oxide. As shown by results of this study, formation of water from the elements at $25^{\circ} \mathrm{C}$ is promoted by the active 
surface of plutonium oxide. Oxidation of dioxide to form $\mathrm{PuO}_{2+x}$ is also significantly more rapid in water than in dry air. As shown by Equation 8 , these catalytic reactions combine in a concerted process that consumes $\mathrm{O}_{2}$ at the accelerated rate of the $\mathrm{Pu}+\mathrm{H}_{2} \mathrm{O}$ reaction and maintains a constant concentration of $\mathrm{H}_{2} \mathrm{O}$ in the system, but does not form $\mathrm{H}_{2}$ as a product. Dissociation of adsorbed $\mathrm{O}_{2}$ according to Equation 12 demonstrates that potential exists for similar catalytic activity of uranium oxide.

\subsubsection{Kinetic behavior in moist air}

A paralinear time dependence for the reaction of uranium is shown by sensitive measurements during the reaction of uranium with moist oxygen [29]. This result is consistent with observations for uranium and plutonium in dry air and in water vapor and confirm that diffusion control occurs during corrosion in moist air.

Arrhenius results show diverse behavior for corrosion of uranium and plutonium in moist air $[2,3]$. The kinetic dependencies of corrosion on temperature and reactant pressures are interrelated and are most easily described in a separate assessment for each metal. Kinetic behavior for reaction of plutonium with moist air parallels that for water vapor. The corrosion rate is independent of oxygen pressure and varies systematically with the square-root of water pressure from dry $\left(<0.4\right.$ mtor $\left.\mathrm{H}_{2} \mathrm{O}\right)$ to saturated conditions [4]. Likewise, the activation energy varies with $\mathrm{PH}_{2} \mathrm{O}$ from the value of $79 \mathrm{~kJ} \mathrm{~mol}^{-1}$ (19 kcal $\left.\mathrm{mol}^{-1}\right)$ in dry air to $141 \mathrm{~kJ} \mathrm{~mol}^{-1}\left(34 \mathrm{kcal} \mathrm{mol}^{-1}\right)$ in moisture-saturated air. The only significant difference is the consumption of $\mathrm{O}_{2}$ instead of $\mathrm{H}_{2} \mathrm{O}$ during reaction.

Kinetic results for oxidation of uranium in moist air shows complex dependencies on temperature, oxygen pressure, and water pressure [2]. Three distinct regions of behavior are observed as $\mathrm{PO}_{2}$ is progressively increased $[2,12]$. At low $\mathrm{O}_{2}$ pressures (<15 mtor), behavior is identical to that observed for plutonium in moist air; the corrosion rate is independent of $\mathrm{PO}_{2}$ and varies as $\mathrm{PH}_{2} \mathrm{O}^{1 / 2}$. In the second kinetic region, the corrosion rate depends on both $\mathrm{PO}_{2}$ and $\mathrm{PH}_{2} \mathrm{O}$. A sharp drop in the rate appears as the oxygen pressure is increased from 15 to $150 \mathrm{mtorr}$, but data are inadequate for quantifying pressure dependence in this region.

In the third kinetic region encountered at $\mathrm{O}_{2}$ pressures greater than 150 mtorr, the corrosion rate of uranium is independent of $\mathrm{PO}_{2}$ and is composed of three temperature regimes. The corrosion rate is not enhanced by moisture at temperatures below $40^{\circ} \mathrm{C}$. At temperatures in the $40-100^{\circ} \mathrm{C}$ range, the corrosion rate is enhanced by the presence of water vapor in excess of an undefined $(<2$ torr) threshold pressure and depends only on temperature with an $\mathrm{E}_{\mathrm{a}}$ of $110 \mathrm{~kJ} \mathrm{~mol}^{-1}\left(26 \mathrm{kcal} \mathrm{mol}^{-1}\right)$. In the high-temperature (100$400^{\circ} \mathrm{C}$ ) regime, the corrosion rate remains independent of $\mathrm{PO}_{2}$, but varies with $\mathrm{PH}_{2} \mathrm{O}$ and 
temperature. The rate varies systematically from zero dependence on water pressure at $100^{\circ} \mathrm{C}$ to $\mathrm{PH}_{2} \mathrm{O}^{1}$ dependence at $250^{\circ} \mathrm{C}$ in accordance with the Langmuir adsorption model [2,32]. $\mathrm{E}_{\mathrm{a}}$ is $56 \mathrm{~kJ} \mathrm{~mol}^{-1}$ ( $\left.13 \mathrm{kcal} \mathrm{mol}^{-1}\right)$ at the median $\mathrm{H}_{2} \mathrm{O}$ pressure of $40 \mathrm{torr}$. A progressive decrease in the dependence of rate on $\mathrm{PH}_{2} \mathrm{O}$ at $250-400^{\circ} \mathrm{C}$ is consistent with increasing instability of adsorbed water at elevated temperatures and coincides with closure of the temperature-humidity envelope.

\subsubsection{A mechanism for oxidation in moist air}

The mechanism for corrosion of uranium and plutonium is defined by the behavior of plutonium and that of uranium at low oxygen pressures. Enhancement of the corrosion rate for uranium is moderated by the presence of a low $\mathrm{O}_{2}$ pressure and modification of the model is necessary to address the complex kinetic behavior of the metal in air.

The proposed mechanism for corrosion of uranium and plutonium in moist air is based on the following observations: (1) Formation of oxide is accompanied by disappearance of $\mathrm{O}_{2}$ from the gas phase at an accelerated rate, maintenance of a constant $\mathrm{H}_{2} \mathrm{O}$ concentration, and the absence of $\mathrm{H}_{2}$ formation. (2) Oxide products are essentially identical to those formed by reaction of dry air and water vapor. (3) The time dependence of reaction is paralinear implying that an oxide diffusion barrier of constant thickness is established. (4) The square-root dependence of corrosion rate on water pressure for plutonium and for uranium at low $\mathrm{O}_{2}$ pressures suggests that the rate depends on the surface concentration of adsorbed hydroxide. (5) Isotopic exchange data show that oxidation proceeds by reaction of $\mathrm{H}_{2} \mathrm{O}$. (6) The corrosion rate in moist air at a given humidity equals that observed for corrosion by water vapor at the same pressure. (7) Isotopic exchange data show that $\mathrm{O}_{2}$ is transformed into $\mathrm{H}_{2} \mathrm{O}$ and into oxide product during corrosion. (8) Formation of water by reaction of $\mathrm{H}_{2}$ and $\mathrm{O}_{2}$ is catalyzed by the oxide surface.

As with corrosion of uranium and plutonium in water vapor, diffusion of $\mathrm{O}^{2-}$ through the steady-state thickness of oxide during reaction in moist air proceeds via the same mechanistic steps as oxidation in dry air. Except for the last step of the mechanism, the chemistry involved in formation of $\mathrm{O}^{2}$ at the gas-oxide interface is identical to that for corrosion in water vapor. As for the reaction of water vapor, a high surface concentration of $\mathrm{OH}^{\prime}$ is formed by chemisorption of $\mathrm{H}_{2} \mathrm{O}$ from moist air according to Equations $\mathrm{I}$ and 2. Adsorbed $\mathrm{OH}$ interacts with an electron to form $\mathrm{O}^{22}$ and adsorbed hydrogen as described by Equation 16. In the presence elemental oxygen, dissociative adsorption of $\mathrm{O}_{2}{ }^{*}$ via Equation 12 forms adsorbed $\mathrm{O}^{*}$ atoms on the oxide surface. Instead of associating to form 
$\mathrm{H}_{2}$, the adsorbed $\mathrm{H}$ atoms produced during formation of $\mathrm{O}^{2-}$ combine with atomic oxygen to form $\mathrm{H}_{2} \mathrm{O}^{*}$ on the catalytic oxide surface.

$$
2 \mathrm{H} \text { (ads) }+\mathrm{O}^{*} \text { (ads) } \rightarrow \mathrm{H}_{2} \mathrm{O}^{*} \text { (ads) } \leftrightarrow \mathrm{H}_{2} \mathrm{O}^{*}(\mathrm{~g}) \text {. }
$$

Product water remains on the surface as adsorbed $\mathrm{H}_{2} \mathrm{O}$, desorbs as gaseous $\mathrm{H}_{2} \mathrm{O}$, or forms $\mathrm{OH}^{+}$and reacts with the metal to form oxide. Diffusion of $\mathrm{O}^{2-}$ through the oxide layer and reaction at the oxide-metal interface occurs as described by Equation 14.

The proposed mechanism accounts for all fundamental chemical and kinetic observations during corrosion of both uranium and plutonium. The behavior is best examined using the sequence of chemical reactions defined by the mechanism.

$$
\begin{gathered}
\mathrm{U}(\mathrm{Pu})(\mathrm{s})+2 \mathrm{H}_{2} \mathrm{O}(\mathrm{ads}) \rightarrow \mathrm{UO}_{2}\left(\mathrm{PuO}_{2}\right)(\mathrm{s})+4 \mathrm{H}(\mathrm{ads}) . \\
\mathrm{O}_{2}^{*}(\mathrm{~g}) \rightarrow 2 \mathrm{O}^{*}(\mathrm{ads}) . \\
\mathrm{HH}(\mathrm{ads})+2 \mathrm{O}^{*}(\mathrm{ads}) \rightarrow 2 \mathrm{H}_{2} \mathrm{O}^{*}(\mathrm{ads}) . \\
\mathrm{U}(\mathrm{Pu})(\mathrm{s})+2 \mathrm{H}_{2} \mathrm{O}(\mathrm{ads})+\mathrm{O}_{2}^{*}(\mathrm{~g}) \rightarrow \mathrm{UO}_{2}\left(\mathrm{PuO}_{2}\right)(\mathrm{s})+2 \mathrm{H}_{2} \mathrm{O}^{*}(\mathrm{ads}) .
\end{gathered}
$$

Corrosion in moist air at the rapid rate of the metal $+\mathrm{H}_{2} \mathrm{O}$ reaction is kinetically favored and proceeds as described by Equation 19. Atomic $\mathrm{H}$ produced by reaction of water is not releases as $\mathrm{H}_{2}$, but combines with dissociatively adsorbed $\mathrm{O}_{2}$ to reform water. The net result is loss of $\mathrm{O}_{2}$ from the gas phase at the rapid rate of the metal $+\mathrm{H}_{2} \mathrm{O}$ reaction until depletion. Continued reaction of $\mathrm{H}_{2} \mathrm{O}$ then produces $\mathrm{H}_{2}$ as shown by the experimental data in Figure 3. Water is included both as reactant and product in Equation 22 to facilitate the discussion of isotopic behavior.

The proposed mechanism readily accounts for transformation of isotopically labeled $\mathrm{O}_{2}$ into labeled $\mathrm{H}_{2} \mathrm{O}$ and for appearance of labeled oxygen in the oxide product. As shown by Equation 18 and Equations $20-21, \mathrm{O}_{2}$ * reacts quantitatively with $\mathrm{H}$ atoms to form adsorbed $\mathrm{H}_{2} \mathrm{O}^{*}$, a product that either desorbs or remains on the oxide surface. The purity of residual $\mathrm{O}_{2}$ * is preserved because this "isotopic exchange" results from the unidirectional chemical reaction defined by Equation 22, not from a process that breaks all chemical bonds and distributes isotopes throughout the system. Each molecule of $\mathrm{H}_{2} \mathrm{O}$ that reacts is replaced by a molecule of $\mathrm{H}_{2} \mathrm{O}^{*}$. Desorption of the $\mathrm{H}_{2} \mathrm{O}^{*}$ product leads to enrichment of the gas phase, whereas its retention as an adsorbate results in formation of $\mathrm{O}^{*} \mathrm{H}^{-}$and appearance of $\mathrm{O}^{*}$ in the oxide product. As expected, isotopic analysis of oxide layers during depth-profile measurements show that the product formed near the surface is highly enriched in the $O$ isotope initially present as water. The mole fraction of water containing the isotope initially present as $\mathrm{O}_{2}$ progressively increases as reaction proceeds. That change in the isotopic 
concentration of water is tracked by a corresponding increase in the concentration of the $\mathrm{O}_{2}$ isotope with increasing depth in the oxide product.

The inability of workers to confirm the isotopic results reported by McD. Baker et al. [29] has lead to questions concerning their validity. Formation of high-purity $\mathrm{H}_{2} \mathrm{O}^{*}$ during reaction of a $\mathrm{H}_{2} \mathrm{O}+\mathrm{O}_{2}{ }^{*}$ mixture is a consequence of a high $\mathrm{O}_{2} *: \mathrm{H}_{2} \mathrm{O}$ molar ratio in the initial mixture and of a depleted $\mathrm{O}_{2}{ }^{*}$ concentration prior to gas analysis. Whereas this experimental configuration results in essentially complete consumption of $\mathrm{H}_{2} \mathrm{O}$ during oxide formation and in a high concentration of $\mathrm{H}_{2} \mathrm{O}^{*}$ in the residual water, highly enriched water cannot be formed by reacting mixtures with fractional $\mathrm{O}_{2} *: \mathrm{H}_{2} \mathrm{O}$ ratios [40].

Deviation of kinetic behavior from the mechanism is observed for corrosion of uranium in moist air. Insight into the enigmatic decrease in moisture enhancement by oxygen is provided by definition of a single mechanism for plutonium and for uranium at low $\mathrm{O}_{2}$ pressures. The chemistry defined by Equations $19-21$ is preserved in moist air, implying that the enhancement process is only throttled, not replaced. Correspondence of kinetic behavior for the two metals at low $\mathrm{PO}_{2}$ directs attention to the reaction of uranium oxide with oxygen and to potential effects of that interaction on adsorption of water as $\mathrm{OH}$ : Enhancement of $U$ corrosion in moist air is absent below $40^{\circ} \mathrm{C}$, but appears in throttled form at higher temperatures and includes a dependence on water pressure at temperatures above $100^{\circ} \mathrm{C}$. These observations suggest that adsorption of water as $\mathrm{OH}$ is degraded by chemical reaction of $\mathrm{O}_{2}$ at the uranium oxide surface and that the degradation process is strongly dependent on temperature.

A plausible explanation for throttled enhancement of uranium corrosion in moist air is suggested by chemical behavior of $U$ in air [28] and by formation of multi-phase oxide layer during corrosion of $\mathrm{Pu}$ [26]. Identification of $\mathrm{U}_{3} \mathrm{O}_{8}$ as a corrosion product during extended reaction of $\mathrm{U}$ in air at $200^{\circ} \mathrm{C}$ suggests that $\mathrm{O}_{2}$ expcsure results in formation of that oxide at the surface of the $\mathrm{UO}_{2+x}$ product layer on the metal. This possibility is consistent with the presence of $\mathrm{PuO}_{2 \pm x}$ and $\mathrm{Pu}_{2} \mathrm{O}_{3 \pm x}$ on $\mathrm{Pu}$ and with the shift in the fractions of these products in the oxide layer with temperature. That shift is driven by the temperature dependence of auto-reduction, a process that transforms the layer from predominately $\mathrm{PuO}_{2}$ at $25^{\circ} \mathrm{C}$ to $\mathrm{Pu}_{2} \mathrm{O}_{3}$ at $250^{\circ}$ [35]. Formation of low-basicity $\mathrm{U}_{3} \mathrm{O}_{8}$ on the oxide surface at low temperature is capable of preventing moisture enhancement by not adsorbing water as $\mathrm{OH}$. As the temperature increases, the surface composition progressively shifts toward $\mathrm{UO}_{2+\times}$, dissociative chemisorption of water becomes increasingly favorable and dependent on $\mathrm{PH}_{2} \mathrm{O}$, and the corrosion rate increases relative to that for dry air. 


\section{Conclusions}

Experimental results show that plutonium dioxide is a reactive and catalytically active material that alters the kinetic behavior of systems containing hydrogen, oxygen, and water. The oxide surface catalyzes the combination of $\mathrm{H}_{2}$ and $\mathrm{O}_{2}$ to form $\mathrm{H}_{2} \mathrm{O}$ at room temperature. Water dissociatively chemisorbs on the oxide at temperatures below $100^{\circ} \mathrm{C}$ and desorbs at higher temperatures. The adsorption-desprption process competes with the slower thermodynamically favored reaction of $\mathrm{H}_{2} \mathrm{O}$ with $\mathrm{PuO}_{2}$ to form $\mathrm{PuO}_{2+\mathrm{x}}$. These observations are applied in defining the corrosion chemistry and in developing a comprehensive mechanism for corrosion of uranium and plutonium in dry air, water vapor, and moist air.

Corrosion kinetics of uranium and plutonium are controlled by properties of the oxide layer formed on the metal surface during the reaction. The high chemical potential driving reaction is the only metallic property of importance. Formation of a steady-state-thickness oxide layer on the metal establishes a diffusion barrier that controls the corrosion rate by determining the rate at which $\mathrm{O}^{2-}$ ions reach the oxide-metal interface. Dissociative chemisorption of water produces a high concentration of $\mathrm{OH}^{-}$on the oxide surface and facilitates formation of $\mathrm{O}^{2}$ at the gas-solid interface. These processes enhance the corrosion rate in moist air and water vapor by increasing the gradient in oxygen concentration across the oxide layer. The complex chemistry of corrosion in moist air is mirrored by the reaction of $\mathrm{PuO}_{2}$ with moist oxygen to form $\mathrm{PuO}_{2+\mathrm{x}}$. The $\mathrm{H}$ atoms produced during formation of higher oxide combine with dissociatively adsorbed $\mathrm{O}_{2}$ in an oxide-catalyzed cycle that reforms $\mathrm{H}_{2} \mathrm{O}$. The same reaction occurs at the oxide surface during corrosion of the metal in moist air. However, the rate of Pu corrosion is many orders of magnitude more rapid than that oxidation of $\mathrm{PuO}_{2}$ because of the large gradient in oxygen concentration across oxide layer.

The comprehensive mechanism for corrosion of uranium and plutonium finds application in assessing potential hazards posed by potentially pyrophoric waste forms containing plutonium metal. Moisture significantly enhances the corrosion rate of $\mathrm{Pu}$ at low temperatures and the associated generation of heat holds potential for initiating a runaway reaction. For example, the corrosion rate in water at $110^{\circ} \mathrm{C}$ and one atmosphere of water pressure equals that for oxidation of metal in dry air at $400^{\circ} \mathrm{C}$ [4]. However, a recent evaluation of the pyrophoric potential posed by plutonium-containing residues leads to the conclusion that autothermic behavior cannot be initiated by the $\mathrm{Pu}+\mathrm{H}_{2} \mathrm{O}$ reaction because the corrosion rate must decreases as temperature increases [6]. That assessment is based on experimental data showing that the corrosion rate decrease by approximately $10^{4}$ 
between 110 and $200^{\circ} \mathrm{C}$. The validity of the assessment rests on the accuracy of those measurements. Definition of the corrosion mechanism shows that moisture enhancement results from the presence of chemisorbed water on the oxide surface. Experimental measurements also show that water desorbs at $150^{\circ} \mathrm{C}$ in the presence of water vapor and imply that the corrosion rate must decrease with increasing temperature. These independent results are totally consistent with the experimental rate data and with entry into a moistureindependent kinetic regime at temperatures greater than $200-215^{\circ} \mathrm{C}[5,6]$.

The formation of explosive mixtures in storage containers of surplus oxide is also of concern. Although the reaction of water and uranium oxide thas apparently not been studied, formation of $\mathrm{H}_{2}$ by that process is expected to occur if freshly prepared $\mathrm{UO}_{2}$ is placed in storage after exposure to moisture. Kinetics of the $\mathrm{UO}_{2}+\mathrm{H}_{2} \mathrm{O}$ reaction may be sufficiently rapid that oxidation is complete if oxide has been exposed to air for an extended period prior to storage. Although formation of an explosive mixture by reaction of water with oxide in an air-filled container has been suggested, that possibility is not credible. Moisture-enhanced corrosion proceeds by combination of $\mathrm{H}$ atoms from the reaction with oxygen to form water, a process that prevents accumulation of $\mathrm{H}_{2}$ as long as $\mathrm{O}_{2}$ remains in the system. This behavior is confirmed by results from McD. Baker et al. in Figure 3 [29], by results of $\mathrm{O}_{2}$-spiking experiments described by Kondo et al. [22], and by experimental observations described of this study.

The complex nature and inadequate understanding of actinide oxide chemistry is evident. A surprisingly consistent picture of the corrosion kinetics of uranium and plutonium in air emerges from the results of this study. The participation of oxides such as $\mathrm{U}_{3} \mathrm{O}_{8}$ and $\mathrm{Pu}_{2} \mathrm{O}_{3}$ and other compounds as catalysts, diffusion barriers, and transport media awaits investigation.

\section{Acknowledgment}

Experimental work was performed at Los Alamos National Laboratory under auspices of Energy Contract W-7405-ENG-36. Evaluation of data and preparation of the report was supported by Safe Sites of Colorado, LLC, P.O. Box 464, Golden, CO.

\section{References}

1. J.M. Haschke, J.C. Martz, Plutonium Storage, in: Encyclopedia of Environmental Analysis and Remediation, Vol. 6, John Wiley, New York, 1998, pp. 3740-3755.

2. J.M. Haschke, J. Alloys Comp., 278 (1998) 149. 
3. J.M. Haschke, T.H. Allen, J.C. Martz, J. Alloys Comp., 271-273 (1998) 211.

4. J.M. Haschke, T.H. Allen, J.L. Stakebake, J. Alloys Comp., 243 (1996) 23.

5. J.G. Schnizlein, D. F. Fischer, J. Electrochem. Soc., 114 (1967) 23.

6. J.M. Haschke, H. K. Fauske, A.G. Phillips, J. Nucl. Mater., submitted for publication (1999).

7. T.H. Allen and J.M. Haschke, Report LA-13537-MS, Los Alamos National Laboratory, Los Alamos, NM, 1999.

8. L.A. Morales, J.M. Haschke, T. H. Allen, Report LA-13597-MS, Los Alamos National Laboratory, Los Alamos, NM, 1999.

9. J.M. Haschke, T.E. Ricketts, Report LA-12999-MS, Los Alamos National Laboratory, Los Alamos, NM, 1995.

10. E.R. Gardner, T.L. Markin, R:S. Street, J. Inorg. Nucl. Chem., 27 (1965) 541.

11. J.M. Haschke, T.E. Ricketts, J. Alloys Comp., 252 (1997) 148.

12. C.A. Colmenares, Prog. Solid State Chem. Prog. Solid State Chem., 15 (1984) 257.

13. B. Lewis, G. v. Elbe, Combustion, Flames and Explosion of Gases, Academic Press, New York, 1953.

14. G. Fiedlander, J.W. Kennedy, J.M. Miller, Nuclear and Radiochemistry, 2nd ed., Chap. 4, John Wiley, New York, 1964.

15. J.C. Beavis, J. Vac. Sci. Technol., 10 (1973) 386.

16. C.A. Colmenares, Prog. Solid State Chem., 9 (1975) 139.

17. J.L. Stakebake, Report RFP-3790, Rockwell International, Rocky Flats Plant, Golden, CO, 1988.

18. H.E. Fotow, J.M. Haschke, S. Yamauchi, The Actinide Hydrides, in: The Chemical Thermodynamics of Actinide Elements and Compounds, Part 9, International Atomic Energy Agency, Vienna, Austria, 1884.

19. J.W. Ward, Properties and Comparative Trends in Actinide-Hydrogen Systems, in: Handbook on the Physics and Chemistry of the Actinides, Vol. 3, Chap. 1, Elsevier, Amsterdam, Netherlands, 1885, pp. 1-74.

20. J.M. Haschke, Hydrolysis of Plutonium: Plutonium-Oxygen Phase Diagram, in: Transuranium Elements: A Half Century, Chap. 40, American Chemical Society, Washington, DC, 1992, pp. 416-425.

21. M. McD. Baker, L.N. Ness, S. Orman, Trans. Faraday Soc., 62 (1966) 2513.

22. T. Kondo, F.H. Beck, M.G. Fontana, Corrosion, 30 (1974) 330. 
23. J.M. Haschke, Report LA-13069-MS, Los Alamos National Laboratory, Los Alamos, NM, 1995.

24. C.A. Colmenares, R. Howell, T. McCreary, Report UCRL-88549, Lawrence Livermore Laboratory, Livermore, CA, 1981.

25. A.G. Ritchie, R.C. Greenwood, S.L. Randles, D.R. Netherton, J.P. Whitehorn, J. Nucl. Mater., (1986) 197.

26. J.L. Stakebake, D.T. Larson, J.M. Haschke, J. Alloys Comp., 202 (1993) 251.

27. W.D. Wilkinson, Uranium Metallurgy, in: Uranium Corrosion and Alloys, Vol. II, Chap. 7, Interscience, New York, 1962, pp. 757-853.

28. M. McD. Baker, L.N. Ness, S. Orman, Trans. Faraday Soc., 62 (1966) 2525.

29. K. Winer, C.A. Colmenares, R. L. Smith, F. Wooten, Surf. Sci., 183 (1987) 67.

30. G.C. Allen, P.M. Tucker, and R.A. Lewis, J. Chem. Soc. Faraday Trans. II, 80 (1984) 991.

31. G.W. McGillivary, D.A. Geeson, and R.C. Greenwood, J. Nucl. Mater., 208 (1994) 81.

32. J.E. Draley, J. Electrochem. Soc., 104 (1957) 329.

33. M.A. Thompson, Observations on the Atmospheric Oxidation of Plutonium Metal, in: Plutonium 1965, Chap. 30, Chapman Hall, London, 1967, pp. 592-602.

34. J.T. Waber, Peaceful Uses of Atomic Energy, 5, (Proceedings of the Second United Nations Conference 1958), United Nations, Geneva, 1958, 204-214.

35. J.C. Martz and J.M. Haschke, J. Nucl. Mater., 210 (1994) 130.

36. J.L. Stakebake and L.A. Lewis, J. Less-Common Metals., 136 (1988) 349.

37. J.L. Stakebake and L.M. Steward, J. Electrochem. Soc., 119 (1972) 730.

38. J.H. Grimes and J.R. Morris, Report 066/65, Atomic Weapons Research Establishment, Aldermaston, Reading, Berkshire, England, 1965.

39. J.H. Grimes and J.R. Morris, Report 068/65, Atomic Weapons Research Establishment, Aldermaston, Reading, Berkshire, England 1965.

40. L.J. Weirick, Report SAND-83-0618, Sandia National Laboratories, Albuquerque, NM, 1984. 
Table 1. Experimental Data and Kinetic Results for the Reaction of a $\mathrm{H}_{2}+\mathrm{O}_{2}$ Mixture Exposed to $\mathrm{PuO}_{2}$ at Room Temperature"

\begin{tabular}{|c|c|c|c|}
\hline \multirow{2}{*}{$\begin{array}{l}\text { Elapsed Time (t) } \\
\text { (days) }\end{array}$} & \multirow[t]{2}{*}{$\begin{array}{c}\text { Total Pressure (P) } \\
\text { (torr) }\end{array}$} & \multicolumn{2}{|c|}{$\begin{array}{c}\text { Reaction Rate (R) } \\
\left(\mu \text { mol } \mathrm{H}_{2} \mathrm{O} / \mathrm{g} \mathrm{PuO}_{2} \mathrm{~d}\right)\end{array}$} \\
\hline & & Experimental & Corrected \\
\hline 0 & 126.7 & -- & -- \\
\hline 0.125 & 125.9 & 0.80 & 0.82 \\
\hline 0.250 & 125.3 & 0.60 & 0.62 \\
\hline 0.375 & 124.8 & 0.50 & 0.51 \\
\hline 0.500 & 124.4 & 0.39 & 0.40 \\
\hline 0.75 & 123.8 & 0.30 & 0.31 \\
\hline 1.0 & 123.3 & 0.25 & 0.26 \\
\hline 1.5 & 122.5 & 0.21 & 0.22 \\
\hline 2.0 & 121.8 & 0.18 & 0.19 \\
\hline 2.5 & 121.3 & 0.13 & 0.14 \\
\hline 3.0 & 120.9 & 0.10 & 0.11 \\
\hline 4.0 & 120.2 & 0.085 & 0.097 \\
\hline 5.0 & 119.6 & 0.079 & 0.091 \\
\hline 10 & 117.0 & 0.065 & 0.077 \\
\hline 15 & 114.5 & 0.064 & 0.075 \\
\hline 20 & 112.3 & 0.055 & 0.067 \\
\hline 25 & 110.3 & 0.050 & 0.062 \\
\hline 35 & 107.0 & 0.041 & 0.053 \\
\hline 45 & 104.3 & 0.038 & 0.050 \\
\hline 50 & 102.3 & $0.034^{c}$ & 0.046 \\
\hline 60 & 99.6 & $0.018^{c}$ & 0.030 \\
\hline 70 & 97.6 & $0.017^{c}$ & 0.029 \\
\hline 130 & 90.0 & $0.010^{c}$ & 0.022 \\
\hline 145 & 88.7 & $0.016^{c}$ & 0.028 \\
\hline
\end{tabular}

a. The initial $\mathrm{D}_{2}: \mathrm{O}_{2}$ ratio of the mixture was $2.27: 1$.

b. Experimental rates are based on the measured $P-t$ data; corrected rates are adjusted for concurrent generation of $\mathrm{H}_{2}$ at the constant rate $\left(12.0 \mathrm{nmol} \mathrm{H} / \mathrm{g} \mathrm{PuO}\right.$ day) of the $\mathrm{PuO}_{2}+\mathrm{H}_{2} \mathrm{O}$ reaction.

c. Whereas rates at low pressures are derived from the incremental $P$ and $t$ changes relative to the preceding data point, this rate is based on $\mathrm{P}-\mathrm{t}$ data measured several days before and after the indicated median time. 
Table 2. Mass Spectrometric Results for the Gas Phase after Different Time Periods during Exposure of the $\mathrm{H}_{2}+\mathrm{O}_{2}$ Reaction Mixture to $\mathrm{PuO}_{2}$ at Room Temperature

\begin{tabular}{cccc}
\hline $\begin{array}{c}\text { Gaseous } \\
\text { Constituent }\end{array}$ & \multicolumn{2}{c}{$\begin{array}{c}\text { Mole Percentage after Indicated } \\
\text { Exposure Period in Days }\end{array}$} \\
\cline { 2 - 4 } & $0^{2}$ & 2.4 & 72 \\
\hline $\mathrm{H}_{2}{ }^{b}$ & 69.43 & 72.13 & 72.41 \\
$\mathrm{O}_{2}$ & 30.55 & 27.62 & 26.38 \\
$\mathrm{CO}_{2}$ & 0.014 & 0.14 & 0.35 \\
& 0.010 & 0.10 & 0.87 \\
\hline
\end{tabular}

a. The molar ratio of $\mathrm{D}_{2}: \mathrm{O}_{2}$ in the initial 'mixture is $2.27: 1$, a value that is approximately equal to the 2:1 ratio for gases produced by radiolytic decomposition of water.

b. The percentages reported of $\mathrm{H}_{2}$ are sums of values measured for $\mathrm{H}_{2}$ and $\mathrm{D}_{2}$. 
Table 3. Quantification of Reactants and Products During Exposure of a $\mathrm{H}_{2}+\mathrm{O}_{2}$ Mixture to $\mathrm{PuO}_{2}$ at Room Temperature"

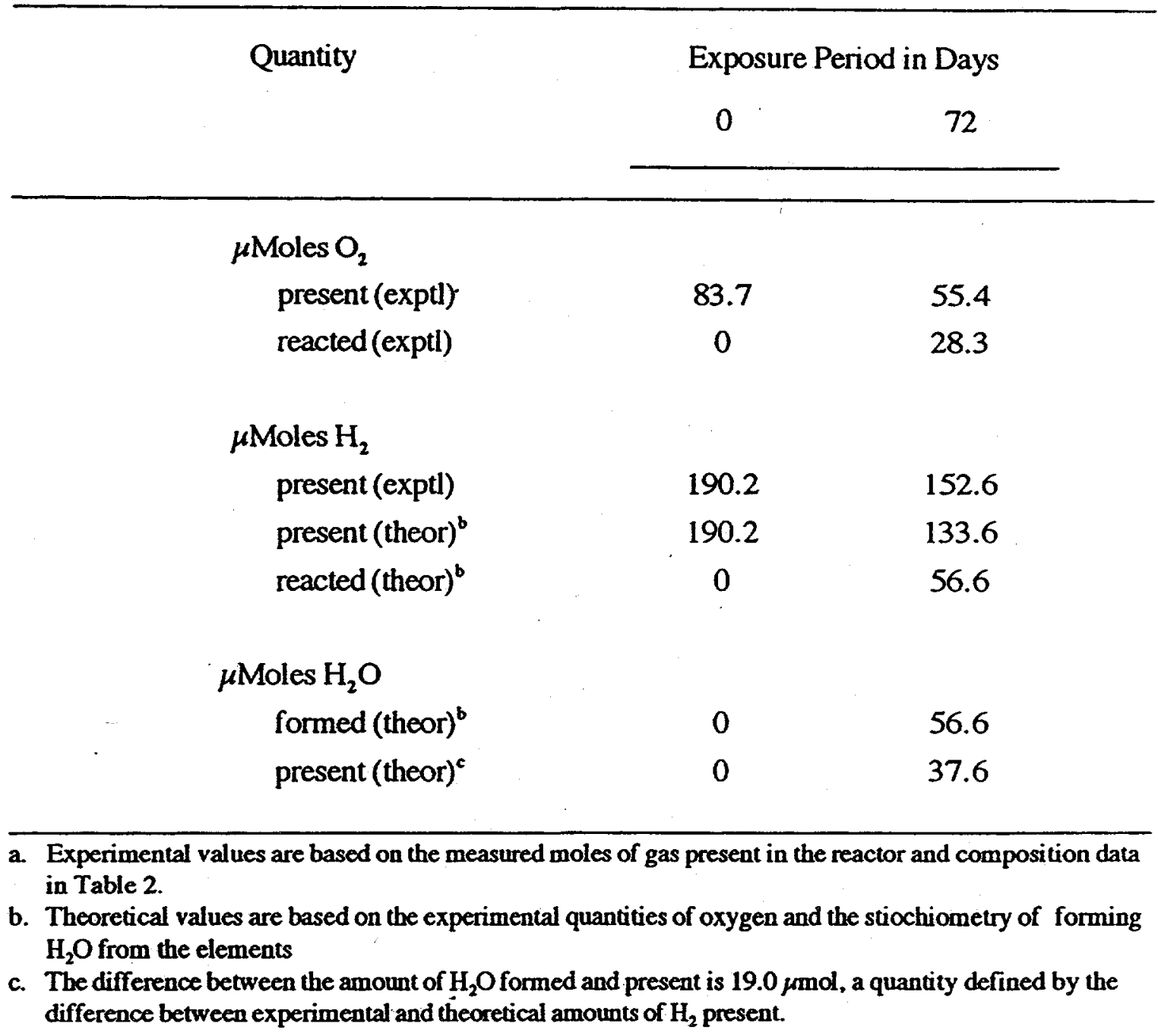


Table 4. Time Dependence of Water Concentration on the Dioxide Surface during Exposure of a $\mathrm{H}_{2}+\mathrm{O}_{2}$ Mixture to $\mathrm{PuO}_{2}$ at Room Temperature

\begin{tabular}{cccc}
\hline $\begin{array}{c}\text { Elapsed Time } \\
(\mathrm{t} \text { in days })\end{array}$ & $\begin{array}{c}\text { Quantity of Water } \\
(\mu \mathrm{mol})\end{array}$ & $\begin{array}{c}\text { Fractional Coverage }^{\mathrm{b}} \\
(\Theta)\end{array}$ \\
\cline { 2 - 3 } & Formed & Remaining \\
1 & 4.0 & 3.9 & 0.013 \\
2 & 7.2 & 6.9 & 0.024 \\
5 & 10.4 & 9.7 & 0.033 \\
10 & 14.8 & 13.4 & 0.056 \\
20 & 22.6 & 19.8 & 0.068 \\
30 & 29.4 & 25.1 & 0.086 \\
50 & 40.3 & 33.4 & 0.114 \\
70 & 48.4 & 38.7 & 0.132 \\
100 & 56.8 & 43.0 & 0.147 \\
130 & 65.1 & 47.2 & 0.161 \\
150 & 69.0 & 48.3 & 0.164 \\
\hline
\end{tabular}

a. The amount of water formed is calculated from the experimental $P$-t data after correction of $P$ for formation of hydrogen a rate of $12.0 \mathrm{nmol} / \mathrm{g} \mathrm{PuO}_{2} \mathrm{~d}$; the amount of water present at each point in time is defined by the amount formed and the amount consumed by reaction.

b. Values of $\Theta$ are calculated using a specific surface area of $4.0 \mathrm{~m}^{2} / \mathrm{g}$ for $\mathrm{PuO}_{2}$ and a water concentration of $0.11 \mathrm{mg} \mathrm{H} \mathrm{H}_{2} \mathrm{O} / \mathrm{m}^{2}$ in the first chemisorbed hydroxide layer. 


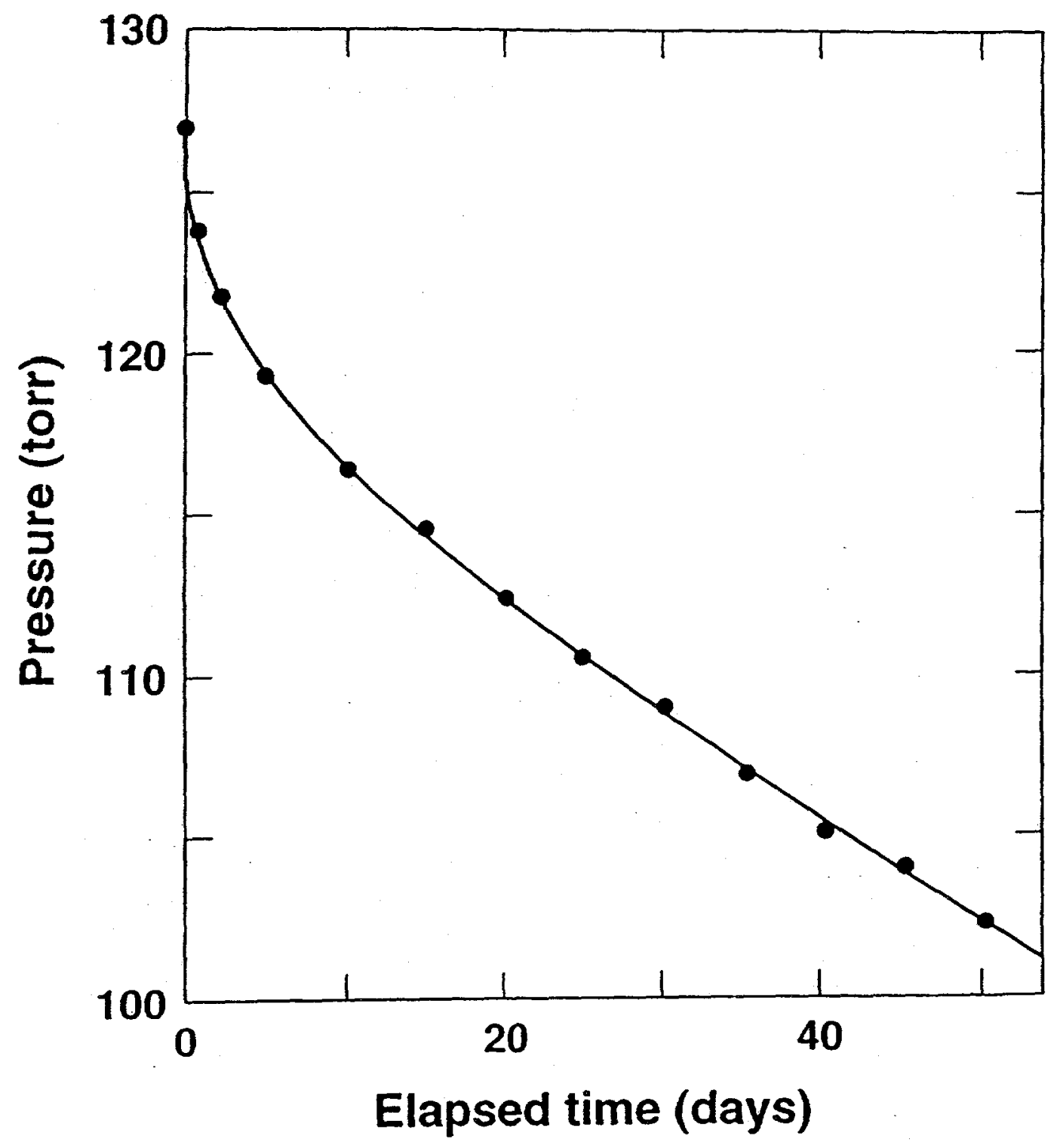

Figure 1. Time dependence of the pressure during exposure of $\mathrm{PuO}_{2}$ to a $2: 1 \mathrm{H}_{2}: \mathrm{O}_{2}$ mixture at $24.5^{\circ} \mathrm{C}$ and an initial pressure of 126.7 torr. 


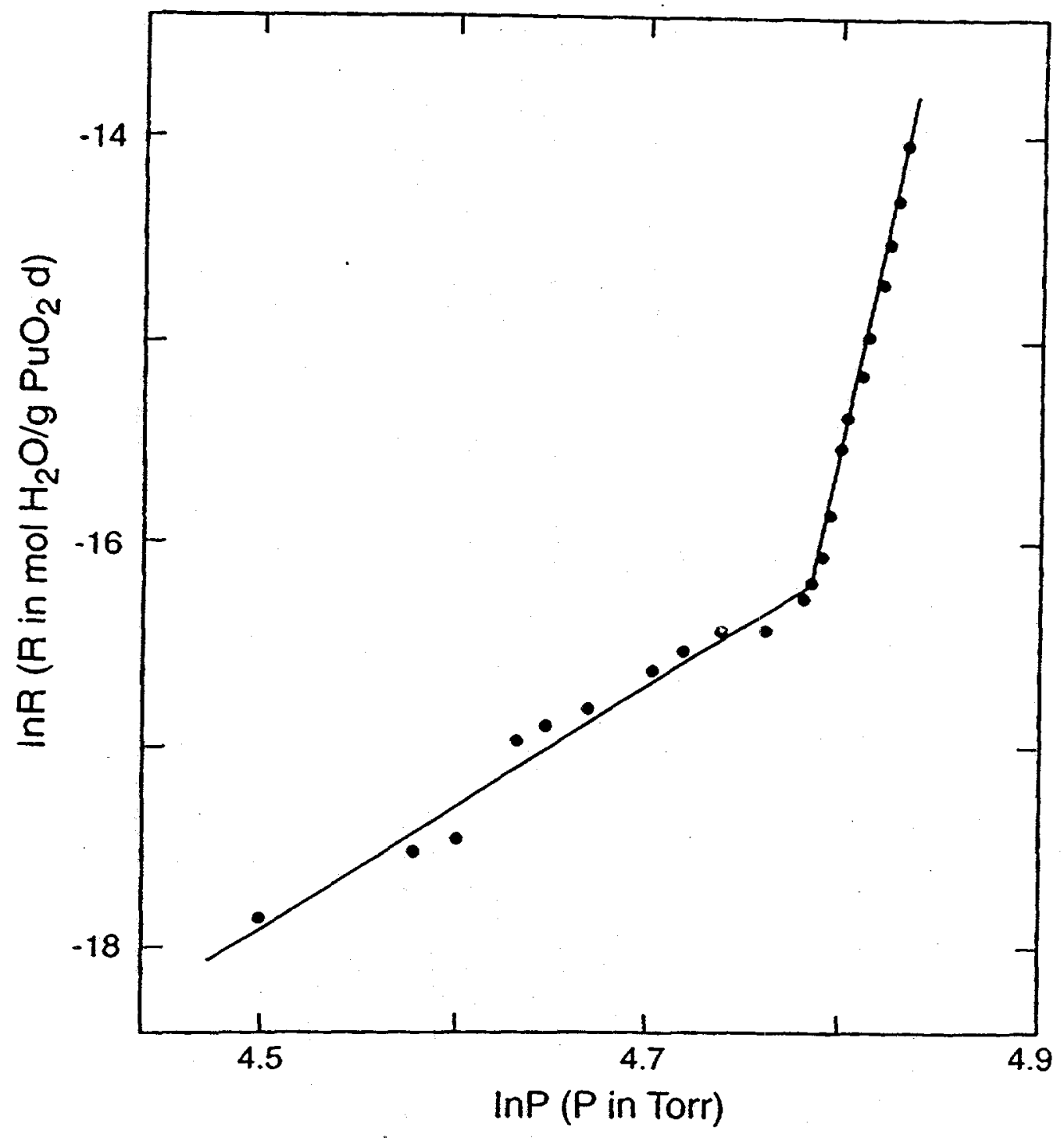

Figure 2. Dependence of $\operatorname{lnR}$ on $\ln \mathrm{P}$ for the $\mathrm{H}_{2}+\mathrm{O}_{2}$ reaction during exposure of $\mathrm{PuO}_{2}$ to a 2:1 $\mathrm{H}_{2}: \mathrm{O}_{2}$ mixture at $24.5^{\circ} \mathrm{C}$. Values of $\mathrm{R}$ and $\mathrm{P}$ are listed in Table 1. 


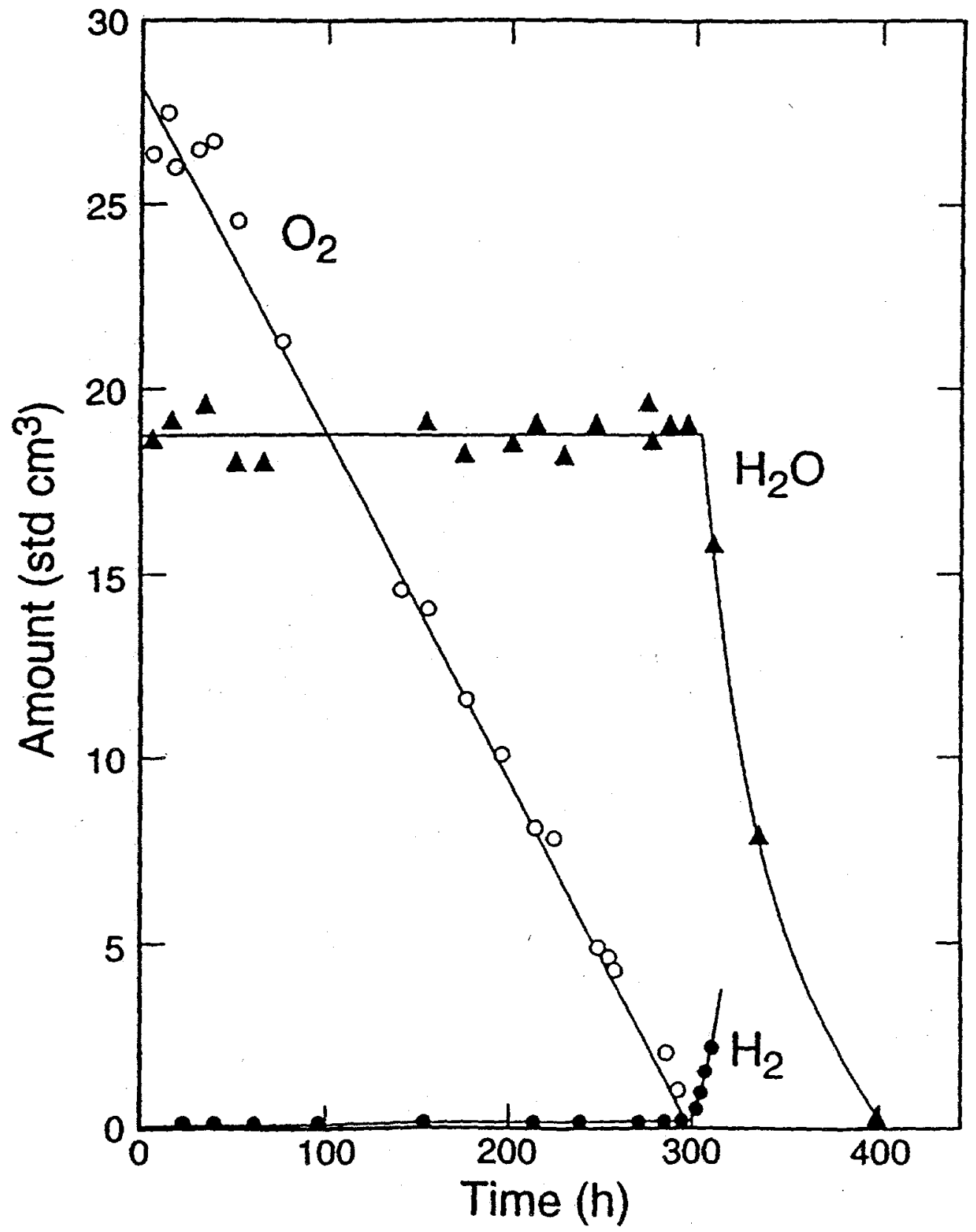

Figure 3. Time dependence of constituents in the gas phase during reaction of uranium metal with a $3: 2 \mathrm{O}_{2}: \mathrm{H}_{2} \mathrm{O}$ mixture at $100^{\circ} \mathrm{C}$. The data are from the report by $\mathrm{McD}$. Baker, Ness, and Orman [29]. 